\title{
Design of a robust PID-PSS for an uncertain power system with simplified stability conditions
}

\author{
Vijaya Lakshmi A.S.V', Ramalinga Raju Manyala ${ }^{2}$ and Siva Kumar Mangipudi ${ }^{3^{*}}$ (D)
}

\begin{abstract}
In a deregulated power system uncertainty exists and lack of sufficient damping can lead to Low Frequency Oscillations (LFO). The problem can be addressed using robust Power System Stabilizers (PSS). In this paper, an optimal procedure to design a robust PID-PSS using interval arithmetic for the Single Machine Infinite Bus (SMIB) power system is proposed. The interval modelling captures the wide variations of operating conditions in bounds of system coefficients. In the proposed design procedure, simple and new closed loop stability conditions for an SMIB interval system are developed and are used to design an optimum PID-PSS for improving the performance of an SMIB system. The optimum PID-PSS is attained by tuning the parameters using the FMINCON tool provided in MATLAB. The robustness of the proposed PID-PSS design is validated and compared to other notable methods in the literature when the system is subjected to different uncertainties. The simulation results and performance error values show the effectiveness of the proposed robust PID-PSS controller.
\end{abstract}

Keywords: Low frequency oscillations, Uncertainty, Power system stabilizer, Robust controller, Interval systems

\section{Introduction}

Synchronous generators are equipped with high gain AVRs to enhance stability margins. However, although high gain AVRs improves the synchronizing torque they have a negative effect on the damping torque. This could result in low frequency oscillation. Transmission networks connected by weak lines are also susceptible to low frequency oscillation. To overcome these problems, synchronous generators are equipped with PSS to provide auxiliary signals to the excitation system [1-7]. The design of conventional PSS parameters is usually based on a fixed operating condition, and hence variation in the operating condition may cause poor performance of PSS and sometimes lead to system instability.

Much research has been carried out in PSS parameter tuning for a wide range of operating conditions that

\footnotetext{
* Correspondence: profsivakumar.m@gmail.com

${ }^{3}$ Department of EEE, Gudlavalleru Engineering College, Gudlavalleru, Andhra Pradesh, India

Full list of author information is available at the end of the article
}

include application of modern tools like ANN and Fuzzy Logic, optimization techniques, FACTS, adaptive controllers and robust controllers etc. A power system is highly nonlinear and therefore PSS design using ANN $[8,9]$ assures good dynamic stability. However, it requires a good training data set covering all types of uncertainties in the system. This is difficult to realize in practice. On the other hand, extensive previous knowledge of system behavior is required for Fuzzy Logic application [10, 11]. Metaheuristic methods [12-18] like PSO, GA, Harmony Search, Fire-fly and Whale Optimization are also used for tuning PSS parameters. In [19] SVC provided with a supplementary damping controller (SDC) is developed for suppression of inter area oscillations, and a PI controller is designed using Kharitonov's theorem by stabilizing sixteen transfer functions. Various techniques have been proposed for the coordination control of PSS and FACTS devices [20-22]. The MRACs proposed in [23] require continuous measurements to determine the error between

\section{Springer Open}

(c) The Author(s). 2020 Open Access This article is licensed under a Creative Commons Attribution 4.0 International License, which permits use, sharing, adaptation, distribution and reproduction in any medium or format, as long as you give appropriate credit to the original author(s) and the source, provide a link to the Creative Commons licence, and indicate if changes were made. The images or other third party material in this article are included in the article's Creative Commons licence, unless indicated otherwise in a credit line to the material. If material is not included in the article's Creative Commons licence and your intended use is not permitted by statutory regulation or exceeds the permitted use, you will need to obtain permission directly from the copyright holder. To view a copy of this licence, visit http://creativecommons.org/licenses/by/4.0/. 
system response and model reference, while a fuzzy observer and regulator are designed in $[24,25]$, and sufficient conditions are derived in terms of LMI inequalities. Methods such as pole placement [26] using state feedback require all the state variable information, whereas model uncertainties are presented as a linear fractional transformation in [27] and the controller is designed using a quadratic performance index resulting in a controller with the same order as the plant. Robust PSS design using $H_{\infty} \& \mu$ synthesis are described in [2831], although finding the weighting factor is an additional task in the $H_{\infty}$ method. The LMI technique [3234] locates all the closed loop poles in a pre-specified bound. The problem of existing uncertainties in the controller gains is addressed in [35] using the so-called resilient control. Soliman et al., [36, 37] use Kharitonov's theorem to design a lead-lag compensator by stabilizing eight extreme polynomials using PSO. In [38] a multiobjective function is developed to minimize the overshoots to keep the control signal within limits. A different approach for robust PSS is developed in [39] using root locus analysis. Design of a robust three-term PSS is given in [40], while necessary and sufficient conditions are derived by using the interval Routh-Hurwitz criterion in [41]. In [42], two controllers, one for excitation and the other for the governor, are proposed to enhance system stability in the case of controller failure. The PSS design for a multi-machine system is developed using a whale optimization technique [43], while the effect of penetration of wind farms on small signal stability is studied in [44]. To cater for the multiple requirements of power systems, a wide area damping controller is designed in [45]. Stability conditions for fixed and interval polynomials are addressed in $[46,47]$, while the MFAC proposed in [48] damps the inter-area LFO. A multiband fractional order PSS design is reported in [49], in which three different frequency bands instead of one are used to damp the LFO, and the advantages of FO-PSS are exploited. In [50], a frequency response matching technique is used to find suitable PSS and TCSC controller parameters. The design of control devices for engineeering applications are explained in [51], whereas the practical data of the Barka-II power station in Oman is used and PSS is designed for one of the gas units in [52].

In most existing methods, control parameters are only tuned for a few operating points and therefore, the controller may fail or degrade its performance when significant deviation in the system operating state occurs. Furthermore, to deal with significant load variation, for each loading condition, e.g., light, nominal or heavy, a separate controller is proposed for the system to ensure the desired dynamic response. This would add additional cost to the system. Some of the proposed methods require extensive system variable information or exhaustive eigenvalue analysis. Therefore, as the system size increases, the complexity and computational efforts also increase. On the other hand, a controller design employing interval systems uses the following methods: 1) Eight extreme polynomials; 2) The Interval Routh Hurwitz criterion; and 3) Image set polynomials for 1024 operating conditions. Even though these methods exhibit robust stability, they require high computational effort. To overcome the above issues, this paper presents a systematic procedure to develop simple and new stability conditions for an interval system. The main advantage of the proposed method is that a single controller with fixed parameters can cope with the uncertainties in the system for a wide range of operating conditions without compromising the desired dynamic performance. Since the controller design formulation is based on system coefficients rather than system variables, the controller exhibits robust stability and performance for unmodelled dynamics like variations in transmission line reactance and machine inertia etc.

In order to eliminate the limitations and drawbacks of the existing methods, in this research work, an SMIB system with varying operating conditions over a specified range, i.e., $P \in[0.2,1.2]$ and $Q \in[-0.4,0.4]$, is considered. This represents fourth-order 1024 linear models (transfer functions) and extreme values are taken as lower and upper coefficients of the interval system. A robust PID-PSS is designed for the SMIB interval system, one that provides sufficient damping for the entire 1024 operating states. The PID-PSS parameters are obtained using the newly developed stability conditions for interval systems, and to ensure the robust performance of the proposed PID-PSS, an objective function at a nominal operating point is defined. The parameters of the proposed controller are tuned by minimizing this objective function while satisfying the specified constraints. To test the efficacy of the proposed controller, the system is subjected to mechanical step disturbance under a wide range of operating states, and simulation results with the proposed controller are compared to the methods in the literature.

This paper is organized as follows. Section 2 describes the problem formulation and Section 3 develops the new stability conditions for robust stability of an SMIB interval system. Section 4 describes the proposed design procedure for tuning the PID-PSS parameters, and Section 5 presents the simulation results to validate the proposed controller. Finally, Section 6 draws the conclusion.

\section{Problem formulation}

Considering a power system consisting of a single machine connected to an infinite bus as shown in Fig. 1, 


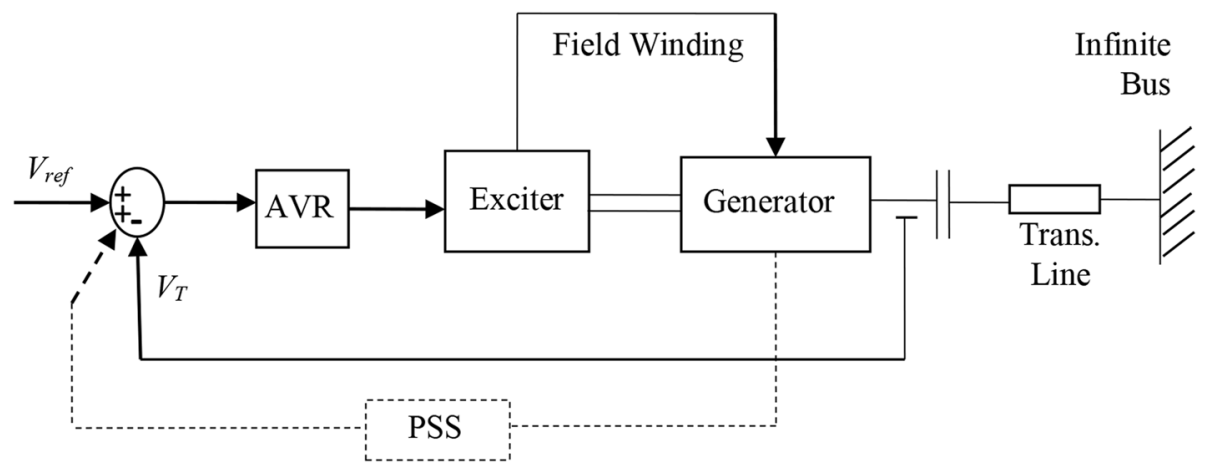

Fig. 1 Basic components of a Single-machine infinite bus power system

the dynamic state of the system can be given by the following non-linear equations:

$$
\left.\begin{array}{l}
\dot{\omega}=\frac{\left(T_{m}-T_{e}\right)}{M} ; \dot{\delta}=\omega_{0} \omega ; T_{e}=E_{q}^{\prime} i_{q}+\left(x_{d}^{\prime}-x_{q}^{\prime}\right) i_{d} i_{q} \\
\dot{E_{q}^{\prime}}=\frac{-E_{q}+E_{f d}}{T_{d o}^{\prime}} ; \dot{E}_{f d}^{\prime}=\frac{1}{T_{E}}\left[-E_{f d}+k_{E}\left(V_{r e f}-V_{t}\right]\right.
\end{array}\right\}
$$

where $\delta$ is the rotor angle, $\omega_{o}$ and $\omega$ are the synchronous speed and rotor angular speed, respectively. $M$ is the inertia constant, $T_{m}$ is the mechanical torque and $T_{e}$ is the electrical torque. $E_{q}{ }^{\prime}$ is the field flux in transient state, $T_{d o}{ }^{\prime}$ is the $\mathrm{d}$-axis open circuit time constant, and $X_{d}{ }^{\prime}$ and $X_{q}{ }^{\prime}$ are the $\mathrm{d}$-and q-axis transient reactances respectively. $E_{f d}$ is the field voltage, $K_{E}$ and $T_{E}$ are the respective gain and time constant of the exciter, $i_{d}$ and $i_{q}$ are the d-and q-axis armature current components, respectively. $V_{\text {ref }}$ and $V_{t}$ are the reference and terminal voltages, respectively. These equations can be linearized around the operating point for small signal stability analysis. This is shown by the block diagram in Fig. 2, developed by Demello and Concordia [1] known as the HeffronPilliphs model.
Except $k_{3}$, the parameters of the model $k_{1}-k_{6}$ are load dependent and their analytical expressions are given in [37]. The transfer function of the plant without PSS can be obtained using Manson's rule for Fig. 2 and is given as:

$$
\begin{aligned}
G(s) & =\frac{\Delta \omega(s)}{\Delta V_{r e f}(s)} \\
& =\frac{-b s}{a_{4} s^{4}+a_{3} s^{3}+a_{2} s^{2}+a_{1} s+a_{o}}
\end{aligned}
$$

The coefficients of the transfer function are:

$$
\left.\begin{array}{l}
a_{4}=M T T_{E} ; a_{3}=M\left(T+T_{E}\right) ; a_{2}=M+314 k_{1} T T_{E}+k_{E} k_{3} k_{6} M \\
a_{1}=314 k_{1}\left(T+T_{E}\right)-314 k_{2} k_{3} k_{4} T_{E} \\
a_{0}=314\left(k_{1}-k_{2} k_{3} k_{4}-k_{E} k_{2} k_{3} k_{5}+k_{E} k_{1} k_{3} k_{6}\right) ; b=k_{E} k_{2} k_{3}
\end{array}\right\}
$$

where $T=k_{3} T_{d o}^{\prime}$.

The coefficients of the transfer function depend on the machine inertia constant, transmission line reactance, field time constant, machine loading conditions and exciter time constant. The load on the system varies continuously and hence the coefficients change for a given

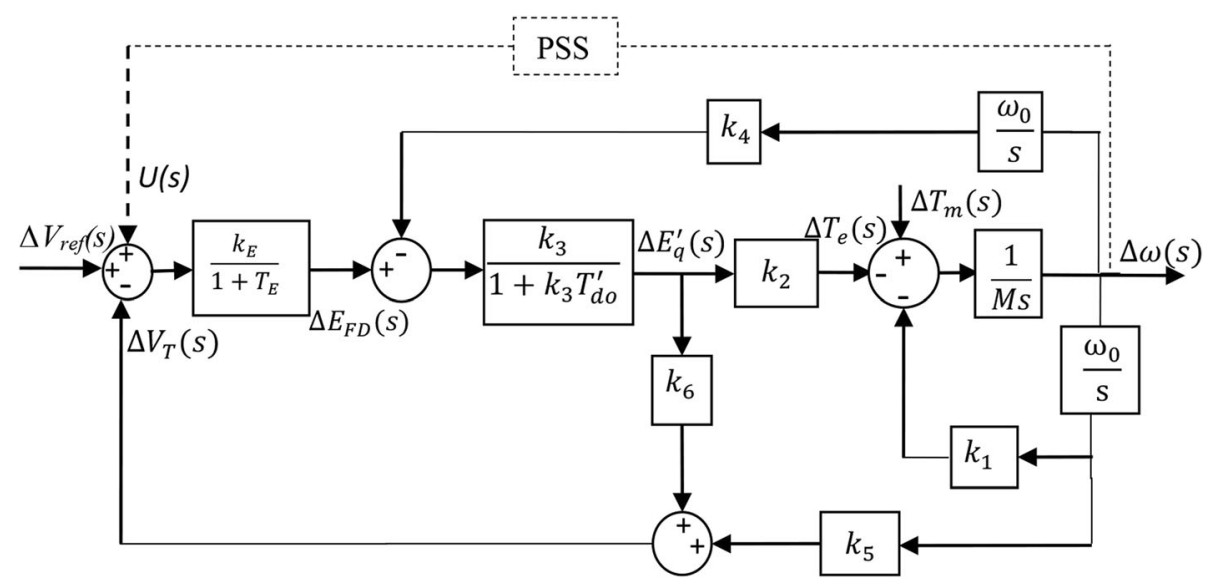

Fig. 2 Linearized model of the SMIB 
system. As the operating point is varied over a specified range, i.e., $P \epsilon\left[\mathrm{P}_{\min }, \mathrm{P}_{\max }\right]$ and $Q \epsilon\left[\mathrm{Q}_{\min }, \mathrm{Q}_{\max }\right]$, the coefficient upper and lower bounds can be determined. Then, the transfer function can be approximated by the following interval polynomial [53]:

$$
G(s)=\frac{N(s, b)}{D(s, a)}=\frac{-\left[b^{-}, b^{+}\right] s}{\left[a_{4}^{-}, a_{4}^{+}\right] s^{4}+\left[a_{3}^{-}, a_{3}^{+}\right] s^{3}+\left[a_{2}^{-}, a_{2}^{+}\right] s^{2}+\left[a_{1}^{-}, a_{1}^{+}\right] s+\left[a_{0}^{-}, a_{0}^{+}\right]}
$$

where

$$
a_{i}^{-}={ }_{P, Q}\left(a_{i}\right) ; a_{i}^{+}={ }_{P, Q}\left(a_{i}\right) ; b^{-}={ }_{P, Q}(b) ; b^{+}={ }_{P, Q}(b)
$$

for $i=1,2,3,4$.

For some operating points, the open loop system is unstable. Hence, a controller needs to be designed to robustly stabilize the system for all operating conditions. Figure 3 shows the equivalent block diagram of the closed loop system, where $G_{c}(s)$ is the transfer function of the controller and $U(s)$ is the controller output.

This paper presents a systematic procedure to design a robust PID-PSS with fixed parameters while the operating point is varied over a specified range, i.e., $P \in\left[\mathrm{P}_{\mathrm{min}}\right.$, $\left.\mathrm{P}_{\max }\right]$ and $Q \epsilon\left[\mathrm{Q}_{\min }, \mathrm{Q}_{\max }\right]$. The stability of the interval polynomials is addressed in [46] using the Nie [47] conditions for a fixed polynomial. New necessary and sufficient conditions for SMIB system are then developed to design the controller parameters of the robust PID-PSS for a specified range of operating conditions.

\section{Development of new stability conditions for robust stability of an SMIB system}

A set of real interval polynomials of degree ' $n$ ' is considered to be in the form of:

$$
D(s, a)=a_{n} s^{n}+a_{n-1} s^{n-1}+\ldots \ldots \ldots \ldots+a_{1} s+a_{0}
$$

where the real coefficient $a_{i}$ varies within a range of lower and upper bounds, i.e.:

$$
a_{i}=\left[a_{i}^{-}, a_{i}^{+}\right] \text {for } i=1,2,3 \ldots . . n \text {. }
$$

It is assumed that the degree of the polynomial remains invariant over the family.

\section{Plant}

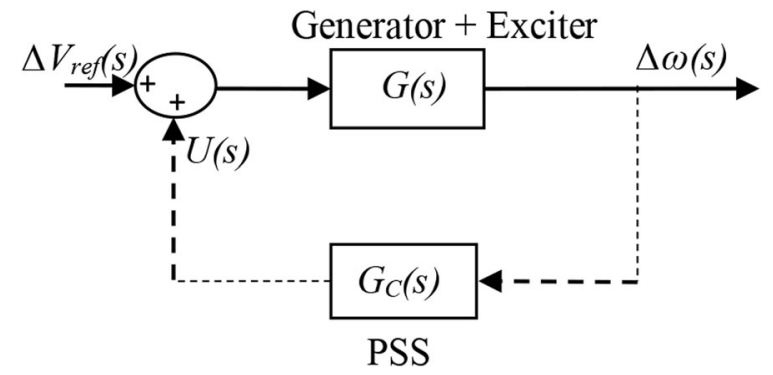

Fig. 3 Equivalent block diagram for the closed-loop system
Such a set of polynomials is called a real interval family and is referred to as an interval polynomial. The set of polynomials given by (5) is stable if and only if each and every element of the set is a Hurwitz polynomial. The necessary and sufficient conditions for the robust stability of interval polynomial (5) are developed using the algebraic stability criterion for fixed polynomials due to Nie [47] and are described below.

\subsection{Nie stability conditions for a fixed polynomial}

Consider a real fixed polynomial of degree ' $n$ ' of the form:

$$
Q(s)=d_{n} s^{n}+d_{n-1} s^{n-1}+\ldots \ldots \ldots \ldots+d_{1} s+d_{0}
$$

\subsubsection{Lemma 3.1.1:}

A necessary condition so that the roots of $Q(s)$ lie in the left half plane is:

$$
\left.\begin{array}{ll}
d_{i}>0 & \text { for } i=0,1,2 \ldots \ldots . n \\
d_{i} d_{i+1}>d_{i-1} d_{i+2} & \text { for } i=1,2 \ldots \ldots \ldots n-2
\end{array}\right\}
$$

\subsubsection{Lemma 3.1.2:}

A sufficient condition so that the roots of $Q(s)$ lie in the left half plane is:

$$
\left.\begin{array}{lr}
d_{i}>0 & \text { for } \quad i=0,1,2 \ldots \ldots \ldots n \\
0.4655 d_{i} d_{i+1}>d_{i-1} d_{i+2} & \text { for } i=1,2 \ldots \ldots \ldots n-2
\end{array}\right\}
$$

\subsection{Stability conditions of the SMIB system with interval coefficients}

The above stability conditions for a fixed polynomial due to Nie [47] are used to obtain the stability conditions for an SMIB system with interval polynomial. These are developed from [46].

\subsubsection{Lemma 3.2.1:}

The interval polynomial $D(s, a)$ defined in (5) is Hurwitz for all $a_{i} \in\left[a_{i}^{-}, a_{i}^{+}\right]$where $i=0,1,2,3 \ldots . . n$, if the following necessary conditions are satisfied:

$$
a_{i}>0 \text { and } a_{i} a_{i+1}>a_{i-1} a_{i+2} \text {. }
$$

These conditions in interval bounds are simplified into the following form:

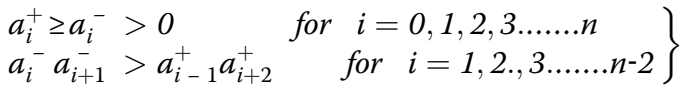

\subsubsection{Lemma 3.2.2:}

The interval polynomial $D(s, a)$ defined in (5) is Hurwitz for all $a_{i} \in\left[a_{i}^{-}, a_{i}^{+}\right]$where $i=0,1,2,3 \ldots . . n$, if the following sufficient conditions are satisfied:

$$
a_{i}>0 \text { and } 0.4655 a_{i} a_{i+1}>a_{i-1} a_{i+2} \text {. }
$$


These conditions in interval bound are simplified into the following form:

$$
\left.\begin{array}{l}
a_{i}^{+} \geq a_{i}^{-}>0 \\
0.4655 a_{i}^{-} a_{i+1}^{-}>a_{i-1}^{+} a_{i+2}^{+} \quad \text { for } i=0,1,2,3 \ldots \ldots n \\
\text { for } i=1,2 ., 3 \ldots \ldots . n-2
\end{array}\right\}
$$

Therefore, for order $n=4$ the stability conditions for the SMIB power system are given by:

$$
\left.\begin{array}{l}
a_{0}^{+} \geq a_{0}^{-}>0 ; a_{1}^{+} \geq a_{1}^{-}>0 ; a_{2}^{+} \geq a_{2}^{-}>0 ; a_{3}^{+} \geq a_{3}^{-}>0 \text { and } a_{4}^{+} \geq a_{4}^{-}>0 \\
\frac{a_{0}^{+} a_{3}^{+}}{a_{1}^{-} a_{2}^{-}}<0.4655 \quad \text { and } \frac{a_{1}^{+} a_{4}^{+}}{a_{2}^{-} a_{3}^{-}}<0.4655
\end{array}\right\}
$$

Using these stability conditions the robust PID-PSS controller for the SMIB system under large uncertainty is developed in the following section.

\section{Procedure for designing robust PID-PSS of a SMIB system}

Power plants in the real world operate under large uncertainties and robust controllers that can stabilize the plants for all the disturbances under all operating conditions are required. This necessitates the development of a new design procedure for determining a robust PID-PSS for an SMIB power system under large uncertainties. The structure of the PID-PSS considered in this work is shown in Fig. 4. As shown, the function of the washout block is to make the PSS inactive under a steady state condition, sudden rejection of heavy loads or system islanding conditions. The gain of the washout block is almost unity and the phase shift is negligible. The addition of the block results in an increase in the number of constraints due to increase in the order of the system. Hence, in the proposed design procedure, the block is omitted, while it is included when validating the efficacy of the controller.

To accommodate the uncertainties of the plant, $P$ and $Q$ are considered in the present work to vary over a wide range, i.e., $P \in\left[\mathrm{P}_{\min }, \mathrm{P}_{\max }\right]$ and $Q \epsilon\left[\mathrm{Q}_{\min }, \mathrm{Q}_{\max }\right]$ with a certain step size.

Step 1: Obtain the SMIB model in transfer function form. The coefficients of the transfer function (2) are computed using (3) for all the operating conditions to obtain the extreme values of the coefficients, given by:

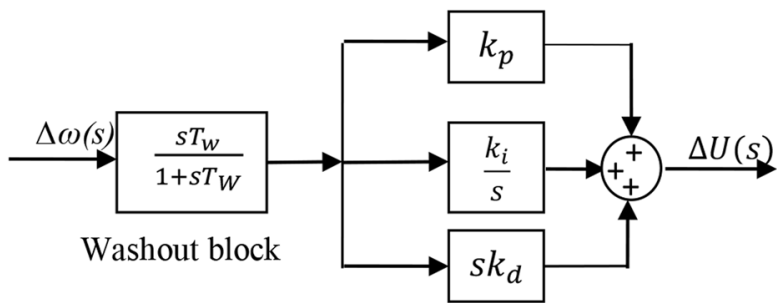

$$
\left.\begin{array}{l}
a_{4}=\left[a_{4}^{-}, a_{4}^{+}\right] ; a_{3}=\left[a_{3}^{-}, a_{3}^{+}\right] ; a_{2}=\left[a_{2}^{-}, a_{2}^{+}\right] ; \\
a_{1}=\left[a_{1}^{-}, a_{1}^{+}\right] ; a_{0}=\left[\begin{array}{l}
a_{0}^{-}, a_{0}^{+} \\
a^{+}
\end{array} ; b=\left[b^{-}, b^{+}\right]\right.
\end{array}\right\}
$$

Step 2: Substitute the above values of coefficients in (2) to obtain the open loop plant transfer function of the SMIB in the interval system given as:

$$
G(s)=\frac{-\left[b^{-}, b^{+}\right] s}{\left[a_{4}^{-}, a_{4}^{+}\right] s^{4}+\left[a_{3}^{-}, a_{3}^{+}\right] s^{3}+\left[a_{2}^{-}, a_{2}^{+}\right] s^{2}+\left[a_{1}^{-}, a_{1}^{+}\right] s+\left[a_{0}^{-}, a_{0}^{+}\right]}
$$

Step 3: Consider the transfer function of the PID-PSS as:

$$
G_{C}(s)=k_{p}+\frac{k_{i}}{s}+k_{d} s
$$

where $k_{p}, k_{i}$ and $k_{d}$ are the proportional, integral and derivative constants of the PID controller, respectively.

Step 4: From Fig. 3, the closed loop transfer function is:

$$
T(s)=\frac{N(s, b)}{D(s, a)}=\frac{G(s)}{1-G(s) G_{c}(s)}
$$

Substituting (13) and (14) into (15), the closed loop transfer function is:

$$
T(s)=\frac{-\left[b^{-}, b^{+}\right] s}{\left[a_{4}^{-}, a_{4}^{+}\right] s^{4}+\left[a_{3}^{-}, a_{3}^{+}\right] s^{3}+\left[a_{2}^{-}+b^{-} k_{d}, a_{2}^{+}+b^{+} k_{d}\right] s^{2}}
$$

Step 5: From (16), the characteristic equation is given by the following interval polynomial as:

$$
\left.\begin{array}{l}
D(s, a)=\left[a_{4}^{-}, a_{4}^{+}\right] s^{4}+\left[a_{3}^{-}, a_{3}^{+}\right] s^{3}+\left[a_{2}^{-}+b^{-} k_{d}, a_{2}^{+}+b^{+} k_{d}\right] s^{2}+ \\
{\left[a_{1}^{-}+b^{-} k_{p}, a_{1}^{+}+b^{+} k_{p}\right] s+\left[a_{0}^{-}+b^{-} k_{i}, a_{0}^{+}+b^{+} k_{i}\right]}
\end{array}\right\}
$$

Step 6: Determine the stability constraints by applying the new stability conditions given in (11) to (17) as:

Constraint 1:

$$
\frac{\left(\left(a_{0}^{+}+b^{+} * k_{i}\right) * a_{3}^{+}\right)}{\left(\left(a_{1}^{-}+b^{-} * k_{p}\right) *\left(a_{2}^{-}+b^{-} * k_{d}\right)\right)}-0.4655<0
$$

Constraint 2:

$$
\frac{\left(\left(a_{1}^{+}+b^{+} * k_{p}\right) * a_{4}^{+}\right)}{\left(\left(a_{2}^{-}+b^{-} * k_{d}\right) * a_{3}^{-}\right)}-0.4655<0
$$

Constraint 3:

$$
\left(-a_{2}^{-}-b^{-} * k_{d}\right)<0
$$

Constraint 4:

$$
\left(-a_{1}^{-}-b^{-} * k_{p}\right)<0
$$

Fig. 4 Block diagram of PID-PSS 
Constraint 5:

$$
\left(-a_{0}^{-}-b^{-} * k_{i}\right)<0
$$

Step 7: To find the controller parameters that exhibit robust performance over the entire range of operating conditions, an objective function is considered as:

$$
J_{\min }=\left\|\frac{k_{p}-k_{p o}}{k_{p o}}\right\|^{2}+\left\|\frac{k_{i}-k_{i o}}{k_{i o}}\right\|^{2}+\left\|\frac{k_{d}-k_{d o}}{k_{d o}}\right\|^{2}
$$

where $k_{p o}, k_{i o}$ and $k_{d o}$ are the PID-PSS controller parameters at the nominal operating point.

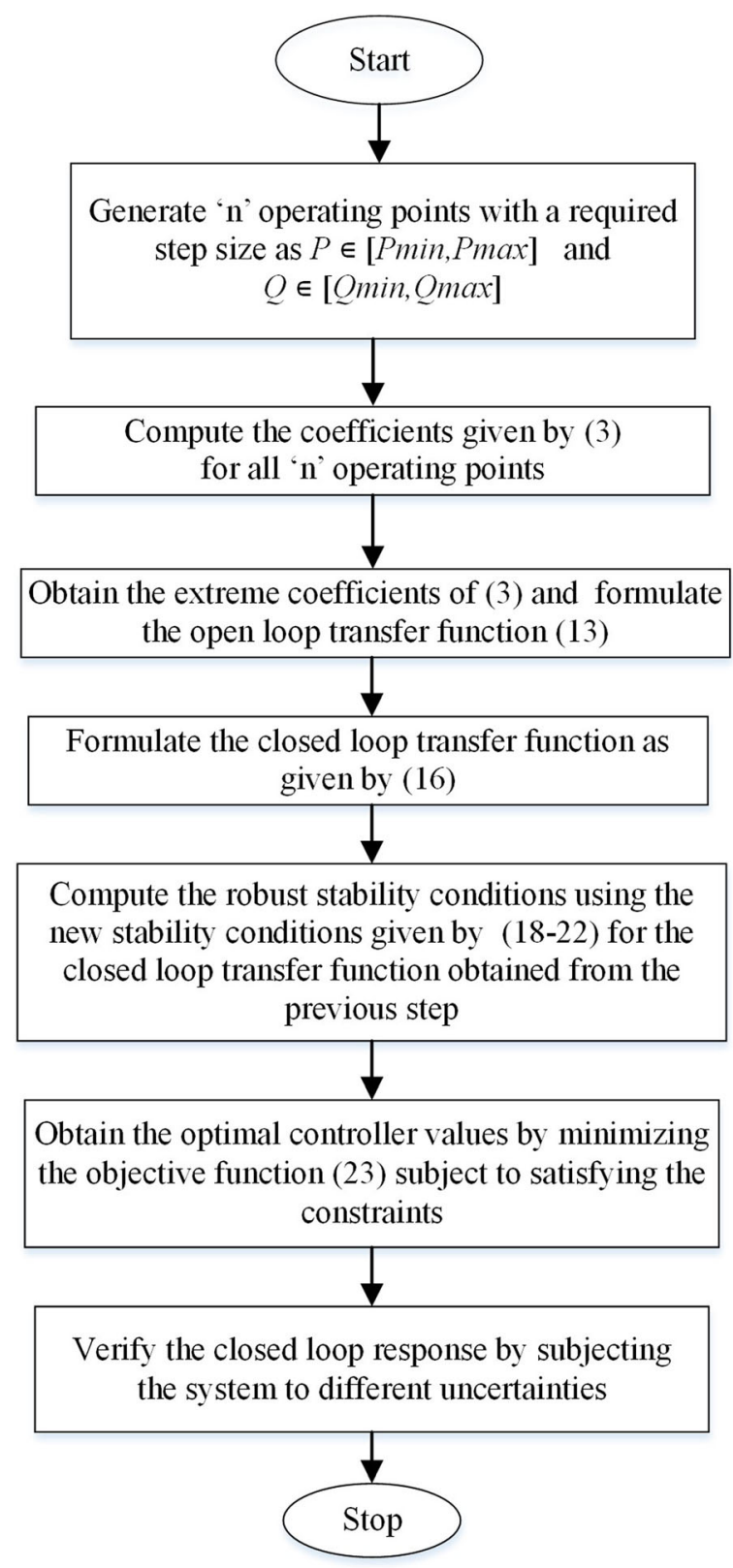

Fig. 5 Flow chart for the proposed robust PID-PSS design
Step 8: The FMINCON function in MATLAB [54], which solves constraint nonlinear optimization problems, is used to obtain the robust PID-PSS parameters, i.e., $k_{p}$, $k_{i}$ and $k_{d}$, by minimizing the objective function (23) while satisfying the developed five constraints (18)-(22). It starts with an initial guess value and finds the minimum of the defined objective function. An interior point algorithm is used in the present work to obtain the optimal controller parameters. The flow chart that represents the proposed design algorithm for obtaining the robust PIDPSS parameters is shown in Fig. 5.

\section{Validation, simulation results and discussion \\ 5.1 Case study I}

The plant shown in Fig. 1 with the machine data given in [37] is considered, and $P$ and $Q$ vary within a wide range of operating conditions, i.e., $P \in[0.2$, $1.2]$ and $Q \in[-0.4,0.4]$, with a suitable step size to have 1024 mesh points. The extreme values of the coefficients are as follows:

$$
\left.\begin{array}{l}
a_{4}=[1,1] ; a_{3}=[22,22] ; a_{2}=[64,106] ; \\
a_{1}=[388,1009] ; a_{0}=[392,2650] ; b=[2.7,12.4]
\end{array}\right\}
$$

Substituting (24) into (13) obtains the open loop transfer function of the plant without PID-PSS controller as:

$$
\begin{aligned}
G(s)= & \frac{\Delta \omega(s)}{\Delta V_{\text {ref }}(s)} \\
= & \frac{-[2.7,12.4] s}{[1,1] s^{4}+[22,22] s^{3}+[64,106] s^{2}} \\
& +[388,1009] s+[392,2650]
\end{aligned}
$$

To determine the stability of the open loop system, the value of the constant $k_{5}$ is computed for all 1024 operating states and is shown in Fig. 6 using a mesh plot. From Fig. 6 , it is observed that the constant $k_{5}$ is negative for some operating points, for example under high active power and leading power factor, the system is relatively more unstable compared to other operating conditions. To illustrate the damping characteristics of

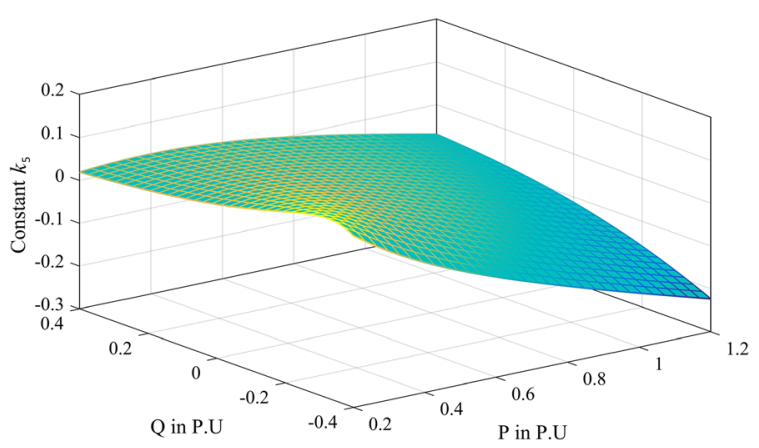

Fig. 6 The constant $k_{5}$ of the open loop system for all 1024 operating conditions 


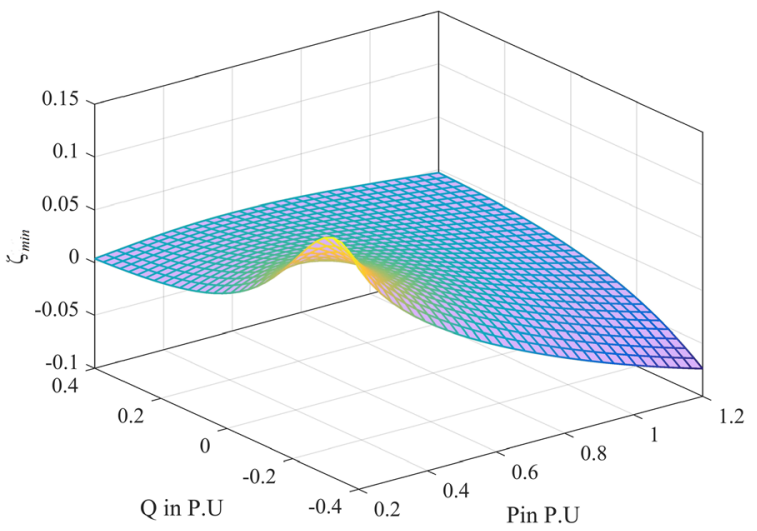

Fig. 7 The minimum damping ratio $\left(\zeta_{\min }\right)$ of the open loop system for all 1024 operating states

the open loop system, the $\zeta_{\min }$ for all 1024 operating points are calculated and are shown in Fig. 7. For some operating points, $\zeta_{\min }$ is negative, indicating poor damping characteristics, which can cause the system to become unstable under uncertainties. A robust PID-PSS controller that makes the closed loop system stable for all 1024 operating states is considered as given by (14). From (16), the resulting closed loop transfer function of the plant is:

$$
\begin{aligned}
T(s)= & \frac{-[2.7,12.4] s}{[1,1] s^{4}+[22,22] s^{3}+\left[64+2.7 k_{d}, 106+12.4 k_{d}\right] s^{2}} \\
& +\left[388+2.7 k_{p}, 1009+12.4 k_{p}\right] s+\left[392+2.7 k_{i}, 2650+12.4 k_{i}\right]
\end{aligned}
$$

From (26) the characteristic equation of the closed loop transfer function is:

$$
\left.\begin{array}{l}
D(s, a)=[1,1] s^{4}+[22,22] s^{3}+\left[64+2.7 k_{d}, 106+12.4 k_{d}\right] s^{2}+[388 \\
\left.+2.7 k_{p}, 1009+12.4 k_{p}\right] s+\left[392+2.7 k_{i}, 2650+12.4 k_{i}\right]
\end{array}\right\}
$$

Applying the new stability conditions in (18)-(22) to (27), the following inequality stability constraints are obtained:

Constraint 1:

$$
\frac{\left[2650+12.4 k_{i}\right] * 22}{\left[388+2.7 k_{p}\right] *\left[64+2.7 k_{d}\right]}-0.4655<0
$$

Constraint 2:

$$
\frac{\left[1009+12.4 k_{p}\right]}{\left[64+2.7 k_{d}\right] * 22}-0.4655<0
$$

Constraint 3:

$$
-64-2.7 k_{d}<0
$$

Constraint 4:

$$
-388-2.7 k_{p}<0
$$

\section{Constraint 5:}

$$
-392-2.7 k_{i}<0
$$

From (30)-(32), the minimum limits for $k_{p}, k_{i}$ and $k_{d}$ for robust stability can be obtained as:

$$
k_{p}^{\min }=-143 ; k_{i}^{\min }=-145 ; \text { and } k_{d}^{\min }=-23
$$

The newly proposed sufficient conditions given by (28) and (29) can be plotted in MATLAB using ezplot as shown in Fig. 8. The Constraint 1 is plotted for different values of $k_{i}$, and it can be seen that the stable region decreases with the increase of $k_{i}$ from ' -145 '. The minimum

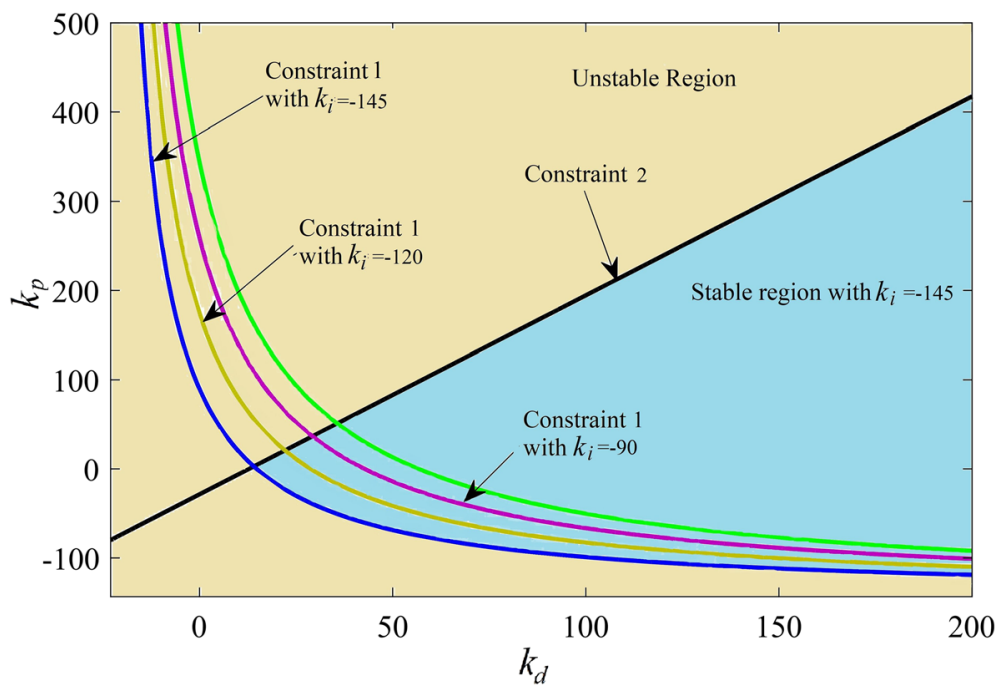

Fig. 8 Stable and unstable regions in the $k_{d}-k_{p}$ plane with a fixed $k_{i}$ for an interval polynomial using proposed stability conditions 
limits for gains are obtained using the new necessary conditions while the maximum limits are arbitrarily chosen. The plot shows the stable and unstable regions obtained from the newly developed stability conditions. Also note that there are a set of controller parameters that can stabilize the plant for all 1024 operating conditions.

The plant characteristic equation at the nominal operating point is given by:

$$
\left.\begin{array}{l}
D(s)=s^{4}+22 s^{3}+\left(97.836+8.768 k_{d o}\right) s^{2}+ \\
\left(856.299+8.768 k_{p o}\right) s+\left(2042.7153+8.768 k_{i o}\right)
\end{array}\right\}
$$

From [51] the optimum coefficients of $D(s)$ that minimize the Integral Time Absolute Error (ITAE) for a step input are given by:

$$
D(s)=s^{4}+2.1 \omega_{0} s^{3}+3.4 \omega_{0}^{2} s^{2}+2.7 \omega_{0}^{3} s+\omega_{0}^{4}
$$

Comparing (34) and (35), the controller parameters at the nominal operating point are:

$$
k_{p o}=256.376, k_{i o}=1129.28 \text { and } k_{d o}=31.4
$$

Since the plant normally operates at the nominal operating point the error between the robust controller parameters and controller parameters at the nominal operating point is minimized. The objective function is obtained by substituting (36) into (23) as:

$$
\begin{aligned}
J_{\min }= & \left\|\frac{k_{p}-256.376}{256.376}\right\|^{2}+\left\|\frac{k_{i}-1129.28}{1129.28}\right\|^{2} \\
& +\left\|\frac{k_{d}-31.4}{31.4}\right\|^{2}
\end{aligned}
$$

The optimal parameters of PID-PSS are obtained by minimizing (37) subject to satisfying the set of inequality constraints (28)-(32). The proposed method is simulated in MATLAB using FMINCON function to solve the set of non-linear inequality constraints, and the obtained

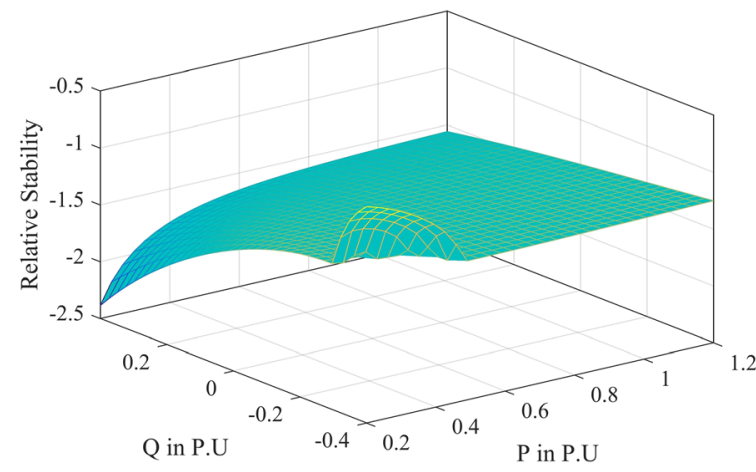

Fig. 9 Relative stability of the closed loop system for all 1024 operating conditions

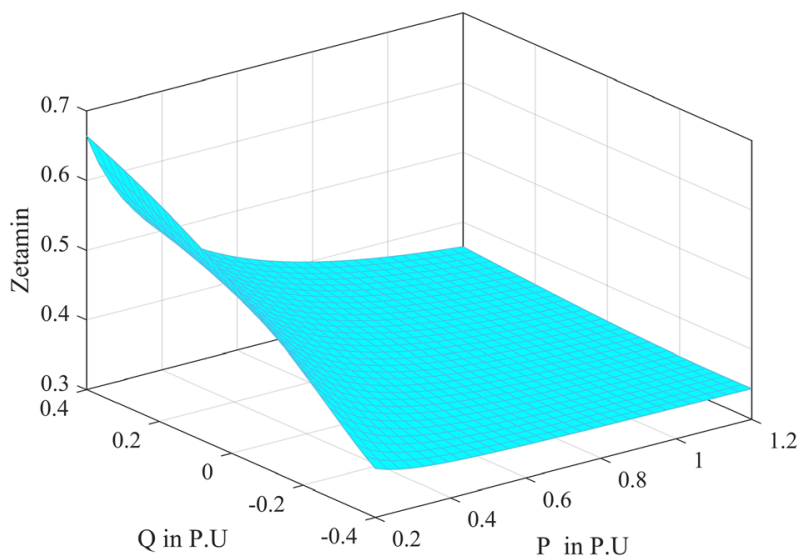

Fig. 10 The minimum damping ratio of the closed loop system for all 1024 operating conditions

optimal controller parameters that robustly stabilize the plant for all 1024 operating conditions are:

$$
k_{p}=98.8226, k_{i}=30 \text { and } k_{d}=57.1044
$$

\subsection{Validation of relative stability $\left(\sigma_{\max }\right)$ and minimum damping ratio $\left(\zeta_{\min }\right)$}

The objective of the proposed work is to design a robust PID-PSS that meets the desired closed loop response for uncertainties present in the system. To achieve the desired response, it must have a minimum damping ratio of 0.25 and relative stability ' $\sigma$ ', i.e., the maximum real part of the roots, must be less than -0.3 , so that system oscillation would settle within 10-15 s. To illustrate the effectiveness of the proposed controller, the relative stability $\left(\sigma_{\max }\right)$ and minimum damping ratio $\left(\zeta_{\min }\right)$ of the closed loop system for all 1024 operating points are computed and are shown in Figs. 9 and 10, respectively.

Table 1 Relative stability and minimum damping ratio for $x_{e}=$ $0.4 \Omega$ with $P$ and $Q$ in p.u

\begin{tabular}{lllllll}
\hline $\mathrm{Q}$ & $\mathrm{P}=0.2$ & $\mathrm{P}=0.4$ & $\mathrm{P}=0.6$ & $\mathrm{P}=0.8$ & $\boldsymbol{P}=1$ & $\boldsymbol{P}=1.2$ \\
\hline \multicolumn{6}{l}{ Relative Stability $\left(\boldsymbol{\sigma}_{\max }\right)$} \\
$\mathbf{- 0 . 4}$ & $-\mathbf{0 . 5 9 9 1}$ & -0.9047 & -1.2777 & -1.2703 & -1.2601 & -1.2488 \\
$\mathbf{- 0 . 2}$ & -1.2424 & -1.2948 & -1.3183 & -1.3247 & -1.3232 & -1.3177 \\
$\mathbf{0}$ & -1.4383 & -1.3757 & -1.3809 & -1.3872 & -1.3888 & -1.3867 \\
$\mathbf{0 . 2}$ & -1.8060 & -1.5422 & -1.4889 & -1.4746 & -1.4688 & -1.4642 \\
$\mathbf{0 . 4}$ & -2.3851 & -1.7942 & -1.6495 & -1.5958 & -1.5709 & -1.5566 \\
$\mathbf{M i n i m u m}$ damping ratio $\left(\boldsymbol{\zeta}_{\min }\right)$ & & & \\
$\mathbf{- 0 . 4}$ & 0.3701 & 0.3517 & 0.3478 & 0.3461 & 0.3451 & $\mathbf{0 . 3 4 3 8}$ \\
$\mathbf{- 0 . 2}$ & 0.4627 & 0.3834 & 0.3610 & 0.3519 & 0.3473 & 0.3446 \\
$\mathbf{0}$ & 0.5465 & 0.4263 & 0.3843 & 0.3652 & 0.3550 & 0.3490 \\
$\mathbf{0 . 2}$ & 0.6119 & 0.4663 & 0.4100 & 0.3818 & 0.3659 & 0.3561 \\
$\mathbf{0 . 4}$ & 0.6643 & 0.4993 & 0.4338 & 0.3988 & 0.3780 & 0.3647 \\
\hline
\end{tabular}


Table 2 Relative stability and minimum damping ratio for $x_{e}=$ $0.8 \Omega$ with $P$ and $Q$ in p.u

\begin{tabular}{|c|c|c|c|c|c|c|}
\hline$Q$ & $P=0.2$ & $P=0.4$ & $P=0.6$ & $P=0.8$ & $P=1$ & $P=1.2$ \\
\hline \multicolumn{7}{|c|}{ Relative Stability $\left(\sigma_{\max }\right)$} \\
\hline-0.4 & -1.1226 & -1.1529 & -1.1026 & -1.0545 & -1.0095 & -0.9677 \\
\hline-0.2 & -1.1544 & -1.2014 & -1.1926 & -1.1665 & -1.1344 & -1.1007 \\
\hline 0 & -1.3007 & -1.2934 & -1.2883 & -1.2727 & -1.2499 & -1.2233 \\
\hline 0.2 & -1.6075 & -1.4763 & -1.4277 & -1.3995 & -1.3744 & -1.3488 \\
\hline 0.4 & -2.0210 & -1.7552 & -1.6261 & -1.5623 & -1.5208 & -1.4877 \\
\hline \multicolumn{7}{|c|}{ Minimum damping ratio $\left(\zeta_{\min }\right)$} \\
\hline & $P=0.2$ & $P=0.4$ & $P=0.6$ & $P=0.8$ & $P=1$ & $P=1.2$ \\
\hline-0.4 & 0.4378 & 0.4330 & 0.4285 & 0.4241 & 0.4196 & 0.4153 \\
\hline-0.2 & 0.5121 & 0.4497 & 0.4327 & 0.4246 & 0.4193 & 0.4150 \\
\hline 0 & 0.5773 & 0.4931 & 0.4534 & 0.4353 & 0.4251 & 0.4184 \\
\hline 0.2 & 0.5234 & 0.5384 & 0.4801 & 0.4515 & 0.4352 & 0.4248 \\
\hline 0.4 & 0.4986 & 0.5725 & 0.5063 & 0.4690 & 0.4470 & 0.4329 \\
\hline
\end{tabular}

It is observed that all the closed loop poles lie in the left half of -0.3 and the maximum $\sigma$ of all 1024 mesh points is $\sigma_{\max }=-0.5991$. The minimum damping ratio is positive for all 1024 mesh points and $\zeta_{\min }=0.3438$ is achieved with the proposed PID-PSS controller. Hence, the proposed controller exhibits robust stability and performance over the entire range of bounded operating conditions.

The relative stability and damping ratio of the closed loop system for some operating points over the range $P$ $\epsilon[0.2,1.2]$ and $Q \epsilon[-0.4,0.4]$ with a step size of 0.2 p.u. are listed in Table 1.

To further validate the robust performance of the proposed controller for other uncertainties such as changes in transmission line reactance due to line outage, machine inertia constant and field time constant, the relative stability $\sigma_{\max }$ and minimum damping ratio $\zeta_{\min }$ are calculated and are listed in Tables 2, 3 and 4.

Assuming the generator is connected to the infinite bus by a double-line circuit with equivalent $x_{e}=0.4 \Omega$, the effect of the transmission line outage can be investigated by considering $x_{e}=0.8 \Omega$ and Table 2 shows the corresponding relative stability and minimum damping ratio.

It can be seen that with the proposed robust PIDPSS, $\sigma_{\max }=-0.9677$ and $\zeta_{\min }=0.4150$. Hence, the relative stability and minimum damping ratio for all the operating points considered are within the desired values. Therefore, the closed loop response for transmission line outage is satisfactory for $P \in[0.2,1.2]$ and $Q \in[-0.4,0.4]$.

With $\pm 30 \%$ changes in field time constant, Table 3 shows that the proposed robust PID-PSS has

Table 3 Relative stability and minimum damping ratio for $\pm 30 \%$ changes in field time constant $T_{d o}$ '

\begin{tabular}{|c|c|c|c|c|c|c|c|}
\hline \multirow{2}{*}{$\begin{array}{l}Q \\
p . u\end{array}$} & \multirow{2}{*}{$\begin{array}{l}\% \\
T_{d o}\end{array}$} & \multicolumn{6}{|l|}{$P$ in $p . u$} \\
\hline & & $\overline{0.2}$ & 0.4 & 0.6 & 0.8 & 1 & 1.2 \\
\hline \multicolumn{8}{|c|}{ Relative Stability $\left(\sigma_{\max }\right)$} \\
\hline \multirow[t]{2}{*}{-0.4} & +30 & -0.5076 & -0.7046 & -1.0904 & -1.4206 & -1.4081 & -1.3942 \\
\hline & -30 & -0.7729 & -1.1345 & -1.1350 & -1.1292 & -1.1292 & -1.1121 \\
\hline \multirow[t]{2}{*}{-0.2} & +30 & -1.4266 & -1.1834 & -1.4920 & -1.4981 & -1.4954 & -1.4882 \\
\hline & -30 & -1.0820 & -1.1360 & -1.1569 & -1.1628 & -1.1620 & -1.1578 \\
\hline \multirow[t]{2}{*}{0} & +30 & -1.7710 & -1.5991 & -1.5876 & -1.5888 & -1.5878 & -1.5834 \\
\hline & -30 & -1.1817 & -1.1782 & -1.1923 & -1.2009 & -1.2038 & -1.2030 \\
\hline \multirow[t]{2}{*}{0.2} & +30 & -2.5395 & -1.8636 & -1.7504 & -1.7163 & -1.7015 & -1.6916 \\
\hline & -30 & -1.3693 & -1.2740 & -1.2568 & -1.2549 & -1.2547 & -1.2535 \\
\hline \multirow[t]{2}{*}{0.4} & +30 & -3.6341 & -2.2863 & -1.9956 & -1.8943 & -1.8479 & -1.8217 \\
\hline & -30 & -1.6257 & -1.4180 & -1.3539 & -1.3303 & -1.3197 & -1.3134 \\
\hline \multicolumn{8}{|c|}{ Minimum damping ratio $\left(\zeta_{\min }\right)$} \\
\hline \multirow[t]{2}{*}{-0.4} & +30 & 0.4167 & 0.3952 & 0.3906 & 0.3888 & 0.3877 & 0.3869 \\
\hline & -30 & 0.3153 & 0.3003 & 0.2970 & 0.2956 & 0.2947 & 0.2939 \\
\hline \multirow[t]{2}{*}{-0.2} & +30 & 0.5246 & 0.4312 & 0.4050 & 0.3945 & 0.3892 & 0.3861 \\
\hline & -30 & 0.3921 & 0.3272 & 0.3087 & 0.3012 & 0.2973 & 0.2950 \\
\hline \multirow[t]{2}{*}{0} & +30 & 0.6237 & 0.4797 & 0.4308 & 0.4086 & 0.3969 & 0.3901 \\
\hline & -30 & 0.4619 & 0.3638 & 0.3290 & 0.3131 & 0.3046 & 0.2996 \\
\hline \multirow[t]{2}{*}{0.2} & +30 & 0.7055 & 0.5240 & 0.4587 & 0.4263 & 0.4081 & 0.3970 \\
\hline & -30 & 0.5156 & 0.3986 & 0.3517 & 0.3281 & 0.3147 & 0.3065 \\
\hline \multirow[t]{2}{*}{0.4} & +30 & 0.6827 & 0.5587 & 0.4836 & 0.4438 & 0.4202 & 0.4052 \\
\hline & -30 & 0.5159 & 0.4284 & 0.3734 & 0.3438 & 0.3261 & 0.3148 \\
\hline
\end{tabular}


Table 4 Relative stability and minimum damping ratio for $\pm 30 \%$ changes in machine inertia constant (M)

\begin{tabular}{|c|c|c|c|c|c|c|c|}
\hline \multirow{2}{*}{$\begin{array}{l}Q \\
\text { p.u. }\end{array}$} & \multirow{2}{*}{$\begin{array}{l}\% \\
M\end{array}$} & \multicolumn{6}{|l|}{$P$ in $p . u$. } \\
\hline & & 0.2 & 0.4 & 0.6 & 0.8 & 1 & 1.2 \\
\hline \multicolumn{8}{|c|}{ Relative Stability $\left(\sigma_{\max }\right)$} \\
\hline \multirow[t]{2}{*}{-0.4} & +30 & -0.6026 & -0.9114 & -1.2797 & -1.2690 & -1.2551 & -1.2400 \\
\hline & -30 & -0.5956 & -0.8983 & -1.2757 & -1.2713 & -1.2647 & -1.2571 \\
\hline \multirow[t]{2}{*}{-0.2} & +30 & -1.2207 & -1.2870 & -1.3128 & -1.3186 & -1.3151 & -1.3069 \\
\hline & -30 & -1.2629 & -1.3023 & -1.3234 & -1.3305 & -1.3309 & -1.3280 \\
\hline \multirow[t]{2}{*}{0} & +30 & -1.3869 & -1.3558 & -1.3678 & -1.3758 & -1.3770 & -1.3733 \\
\hline & -30 & -1.4846 & -1.3943 & -1.3932 & -1.3980 & -1.4001 & -1.3994 \\
\hline \multirow[t]{2}{*}{0.2} & +30 & -1.7087 & -1.5090 & -1.4679 & -1.4577 & -1.4529 & -1.4479 \\
\hline & -30 & -1.8812 & -1.5722 & -1.5084 & -1.4905 & -1.4838 & -1.4796 \\
\hline \multirow[t]{2}{*}{0.4} & +30 & -2.2016 & -1.7473 & -1.6206 & -1.5733 & -1.5509 & -1.5372 \\
\hline & -30 & -2.4677 & -1.8335 & -1.6755 & -1.6164 & -1.5895 & -1.5748 \\
\hline \multicolumn{8}{|c|}{ Minimum damping ratio $\left(\zeta_{\min }\right)$} \\
\hline \multirow[t]{2}{*}{-0.4} & +30 & 0.4230 & 0.4024 & 0.3980 & 0.3960 & 0.3946 & 0.3935 \\
\hline & -30 & 0.3089 & 0.2932 & 0.2899 & 0.2886 & 0.2878 & 0.2873 \\
\hline \multirow[t]{2}{*}{-0.2} & +30 & 0.5275 & 0.4379 & 0.4126 & 0.4023 & 0.3970 & 0.3938 \\
\hline & -30 & 0.3870 & 0.3202 & 0.3013 & 0.2937 & 0.2899 & 0.2876 \\
\hline \multirow[t]{2}{*}{0} & +30 & 0.6247 & 0.4869 & 0.4391 & 0.4173 & 0.4057 & 0.3988 \\
\hline & -30 & 0.4554 & 0.3559 & 0.3208 & 0.3048 & 0.2963 & 0.2913 \\
\hline \multirow[t]{2}{*}{0.2} & +30 & 0.6329 & 0.5339 & 0.4689 & 0.4366 & 0.4183 & 0.4071 \\
\hline & -30 & 0.5038 & 0.3882 & 0.3419 & 0.3185 & 0.3053 & 0.2972 \\
\hline \multirow[t]{2}{*}{0.4} & +30 & 0.6203 & 0.5748 & 0.4973 & 0.4566 & 0.4325 & 0.4172 \\
\hline & -30 & 0.5333 & 0.4135 & 0.3609 & 0.3323 & 0.3151 & 0.3041 \\
\hline
\end{tabular}

satisfactory closed loop response for all the operating states with $\sigma_{\max }=-0.5076$ and $\zeta_{\min }=0.2939$. From Table 4 , it is observed that with $\pm 30 \%$ changes in machine inertia constant, $\sigma_{\max }=-0.5956$ and $\zeta_{\min }=$ 0.2873 , indicating desired performance by the proposed robust PID-PSS.

Hence, we can conclude that the proposed PID-PSS exhibits robust stabilization and performance for the uncertainties presented in the system, since the proposed PID-PSS parameters are tuned for variations in system coefficients rather than system variables.

\subsection{Simulation results and discussion}

To further test the efficiency of the proposed PID-PSS comparing with the existing controllers in literature, the $k$-constants, i.e., $k_{1}-k_{6}$ are calculated for light, nominal, full and overload conditions. Using the MATLABSIMULINK tool box, Fig. 2 is simulated for the above specified operating conditions with $T_{W}=5$ and $k_{p}=$ 98.8226, $k_{i}=30, k_{d}=57.1044$. The uncertainty in the system is provided by a small mechanical step disturbance.

\subsubsection{Full load operating point}

Figure 11 shows the simulation results when the system is operated at $P=1.0$ p.u. and $Q=-0.4$ p.u., and is subjected to a mechanical disturbance of 0.1 p.u. at 0.5 s. It can be observed that without a controller, the plant is unstable to the given disturbance. With the proposed controller, the system is stable and the oscillation in

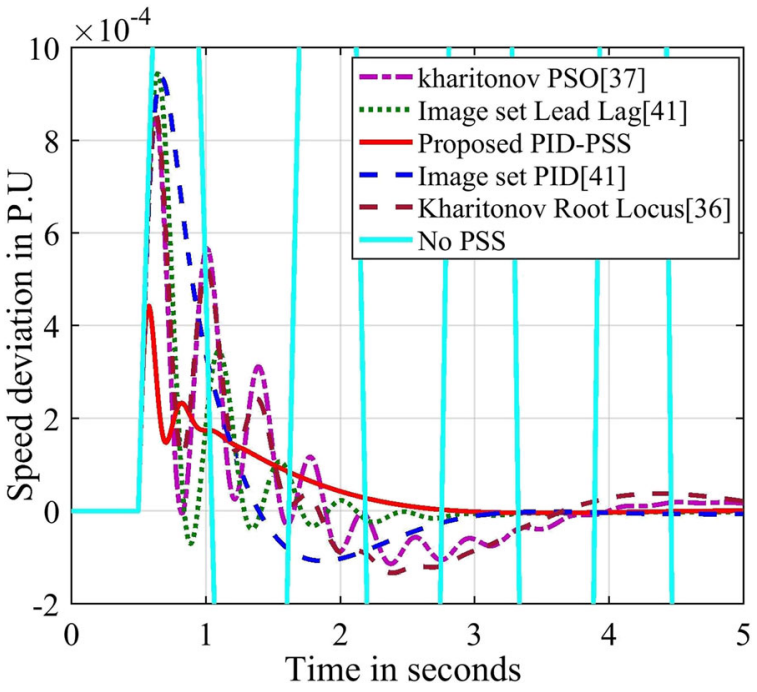

Fig. 11 Comparision of speed deviation response of the proposed with existing methods to 0.1 p.u torque disturbance at $P=1$ p.u. and $Q=-0.4$ p.u 
Table 5 Comparision of performance measures between the proposed and existing methods at $P=1$ p.u. and $Q=-0.4 p . u$

\begin{tabular}{|c|c|c|c|c|c|}
\hline $\begin{array}{l}\text { Time domain specifications/ } \\
\text { Performance Indices }\end{array}$ & $\begin{array}{l}\text { Kharitonov Poly } \\
\text { Root Locus [36] }\end{array}$ & $\begin{array}{l}\text { Kharitonov Poly } \\
\text { PSO [37] }\end{array}$ & $\begin{array}{l}\text { Image set } \\
\text { Lead-Lag [41] }\end{array}$ & $\begin{array}{l}\text { Image set } \\
\text { PID-PSS [41] }\end{array}$ & $\begin{array}{l}\text { Proposed } \\
\text { PID-PSS }\end{array}$ \\
\hline Rise Time & 0.0013 & 0.0044 & $3.4553 \mathrm{e}-4$ & 0.0060 & $1.5920 \mathrm{e}-4$ \\
\hline Settling Time & 5.123 & 5.591 & 2.894 & 2.981 & 2.459 \\
\hline Peak value & $8.4693 \mathrm{e}-4$ & $8.5472 \mathrm{e}-4$ & $9.4378 \mathrm{e}-4$ & $9.3149 \mathrm{e}-4$ & $4.4416 \mathrm{e}-4$ \\
\hline Peak time & 0.6300 & 0.6300 & 0.6400 & 0.6700 & 0.5800 \\
\hline ISE & $1.7344 \mathrm{e}-7$ & $1.6359 \mathrm{e}-7$ & $1.5757 \mathrm{e}-7$ & $2.4247 e-7$ & $0.4147 e-7$ \\
\hline IAE & $5.2443 \mathrm{e}-4$ & $4.5540 \mathrm{e}-4$ & $3.1390 \mathrm{e}-4$ & $4.7086 \mathrm{e}-4$ & $2.2977 \mathrm{e}-4$ \\
\hline ITSE & $1.6253 \mathrm{e}-7$ & $1.4751 \mathrm{e}-7$ & $1.1311 \mathrm{e}-7$ & $1.8707 \mathrm{e}-7$ & $0.3529 \mathrm{e}-7$ \\
\hline ITAE & $8.8001 \mathrm{e}-4$ & $6.9924 \mathrm{e}-4$ & $3.2520 \mathrm{e}-4$ & $5.4516 \mathrm{e}-4$ & $2.7949 \mathrm{e}-4$ \\
\hline
\end{tabular}

speed deviation is less and reaches the steady state within a shorter time than the existing methods.

Table 5 shows that the proposed controller leads to better time domain specifications and has a better performance than the existing methods. The terminal voltage deviation during disturbance shown in Fig. 12 is within limits and the steady-state error is less than that of the other methods. Hence, the proposed controller exhibits robust performance even when the system is operating at full load and leading power factor at which the damping factor is poor.

\subsubsection{Light load operating point}

In this case the plant is operated at a light load condition at leading power factor i.e., $P=0.2$ p.u. and $Q=-0.4$ p.u.. At $0.5 \mathrm{~s}$ a 0.1 p.u. step mechanical disturbance is applied to the plant. From Fig. 13 without a controller, the plant is stable for uncertainty in the load but the settling time is long and peak overshoot is high. With the PID-PSS in



Fig. 12 Comparision of terminal voltage deviation response of the proposed with existing methods to 0.1 p.u. torque disturbance at $P=1$ p.u. and $Q=-0.4$ p.u
[41] shown in Fig. 14, the settling time and terminal voltage deviations are also very large, whereas with the proposed PID-PSS, the time domain specifications are within acceptable limits. In general, the settling time should be less than 10-15 s for satisfactory dynamic performance. Table 6 shows that the proposed robust PID-PSS has better overall performance than the other methods.

\subsubsection{Nominal load operating point}

The plant is operated at a lagging power factor and 10\% mechanical step disturbance is induced. Figure 15 shows that the peak overshoot is low and the steady-state error in terminal voltage deviation shown in Fig. 16 is almost zero. Table 7 shows that the proposed robust PID-PSS has superior overall performance than the other controllers in literature. Therefore it can be concluded that the proposed controller gives the best performance at this operating point compared to other available controllers in the literature.



Fig. 13 Comparision of speed deviation response of the proposed with existing methods to 0.1 p.u. Torque disturbance at $P=0.2$ p.u. and $Q=-0.4$ p.u 


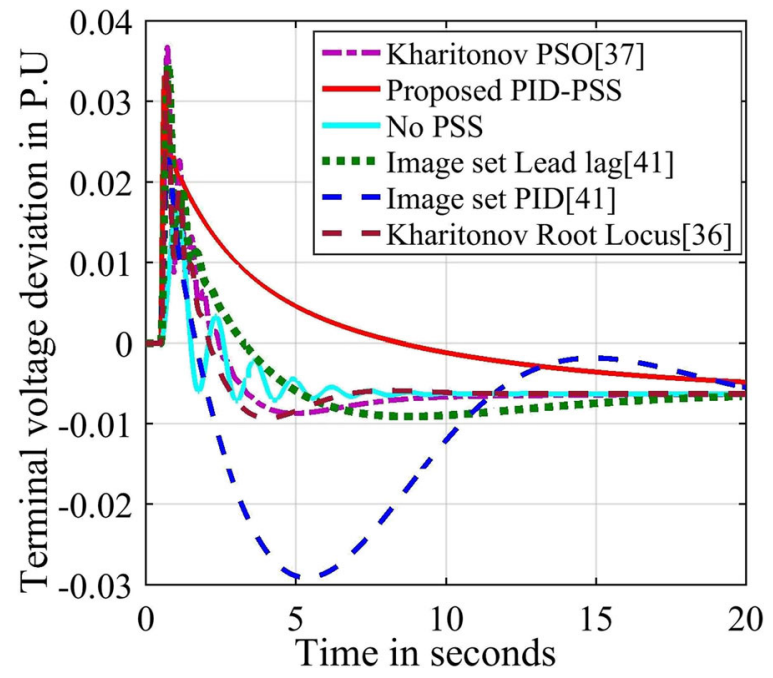

Fig. 14 Comparision of terminal voltage deviation response of the proposed with existing methods to 0.1p.u. Torque disturbance at $P=0.2$ p.u. and $Q=-0.4 p . u$

\subsubsection{Over load operating point}

The machine is operated at $P=1.2$ p.u. and $Q=0.2$ p.u. and is again exposed to a mechanical disturbance of 0.1 p.u.. From Fig. 17, it can be seen that without PSS the disturbance pushes the machine from stable mode to unstable mode. With the addition of PSS in the feedback loop the system regains its stability. With the proposed controller, the peak overshoot of speed deviation is less but the terminal voltage variation is higher when compared to other controllers, as seen from Fig. 18. However, the $\Delta V_{t}$ is within acceptable limits. Table 8 shows that the proposed robust PID-PSS has lesser time domain specifications and performance errors than the other notable controllers in literature. Hence, it can be concluded that the proposed PID-PSS gives robust performance over all operating points compared to the existing controllers.

\subsection{Case study II}

The system considered is a real plant, i.e., Barka II power station in Oman. It consists of three steam units each

Table 6 Comparision of performance measures between the proposed and existing methods at $P=0.2$ p.u. and $Q=-0.4 p . u$

\begin{tabular}{llllll}
\hline $\begin{array}{l}\text { Timedomain } \\
\text { specifications/ } \\
\text { Performance Indices }\end{array}$ & $\begin{array}{l}\text { Kharitonov } \\
\text { Poly Root } \\
\text { Locus [36] }\end{array}$ & $\begin{array}{l}\text { Kharitonov } \\
\text { Poly PSO } \\
{[37]}\end{array}$ & $\begin{array}{l}\text { Image set } \\
\text { Lead-Lag } \\
{[41]}\end{array}$ & $\begin{array}{l}\text { Image set } \\
\text { PID-PSS } \\
{[41]}\end{array}$ & $\begin{array}{l}\text { Proposed } \\
\text { PID-PSS }\end{array}$ \\
\hline Rise Time & $1.5416 \mathrm{e}-4$ & 0.1295 & $2.4178 \mathrm{e}-4$ & 2.4337 & $\mathbf{4 . 4 0 3 1 e - 4}$ \\
Settling Time & 6.234 & $\mathbf{5 . 2 4 8}$ & 6.029 & 16.260 & 6.059 \\
Peak value & $9.2209 \mathrm{e}-4$ & $9.1194 \mathrm{e}-4$ & 0.0010 & 0.0010 & $\mathbf{4 . 8 2 3 2 e - 4}$ \\
Peak time & 0.6400 & 0.6400 & 0.6600 & 0.7 & $\mathbf{0 . 5 8 0 0}$ \\
ISE & $4.7748 \mathrm{e}-7$ & $4.0880 \mathrm{e}-7$ & $3.3331 \mathrm{e}-7$ & $9.6953 \mathrm{e}-7$ & $\mathbf{1 . 0 8 6 7 e - 7}$ \\
IAE & 0.012 & 0.011 & 0.0010 & 0.0022 & $\mathbf{7 . 1 3 8 2 e - 4}$ \\
ITSE & $6.4033 \mathrm{e}-\mathbf{7}$ & $5.5919 \mathrm{e}-7$ & $4.3636 \mathrm{e}-7$ & $1.7878 \mathrm{e}-6$ & $\mathbf{1 . 7 9 0 5 e - 7}$ \\
ITAE & 0.0022 & 0.0021 & 0.0026 & 0.0066 & $\mathbf{0 . 0 0 2 1}$ \\
\hline
\end{tabular}

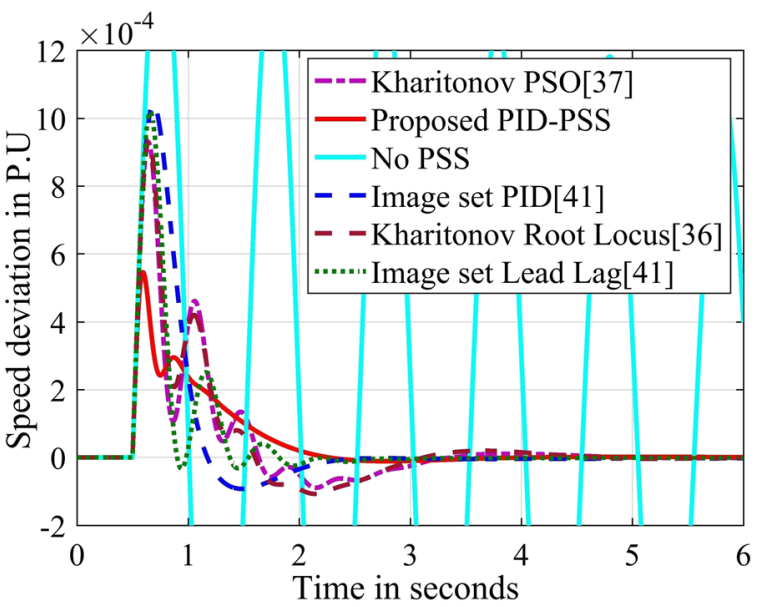

Fig. 15 Comparision of speed deviation response of the proposed with existing methods to 0.1 p.u. torque disturbance at $P=0.8$ p.u. and $Q=0.3$ p.u

rated at 200MVA and two gas units each rated at 175MVA. The PSS is designed for one of the gas units, while the rest of the plant, i.e., the other 4 units and the Oman grid are represented by a Thevenin's equivalent impedance and infinite bus. The data is taken from [48], and three operating conditions, i.e., light, nominal and heavy load covering the whole operating region, are considered for design purposes. From these three loading conditions, extreme values of the coefficients are obtained as:

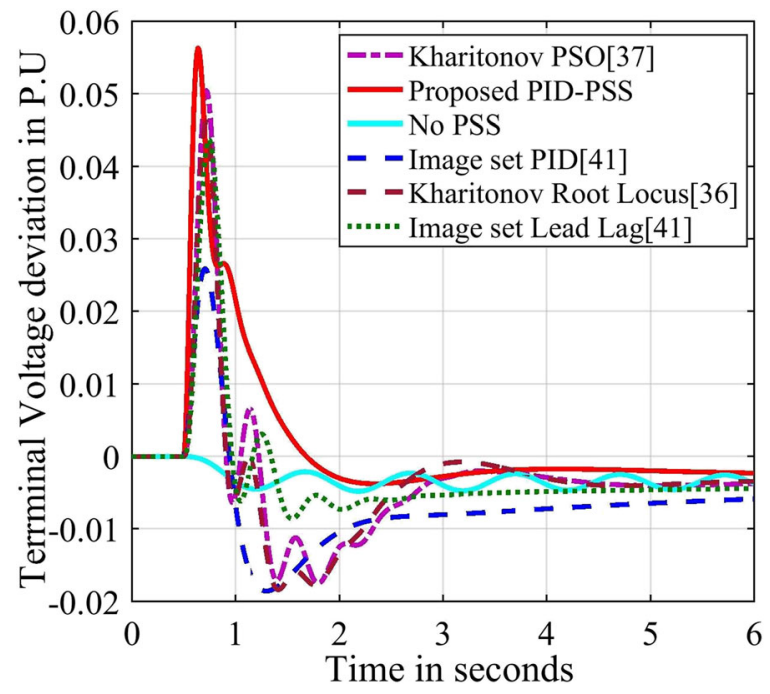

Fig. 16 Comparision of terminal voltage deviation response of the proposed with existing methods to 0.1 p.u. torque disturbance at $P=0.8$ p.u. and $Q=0.3$ p.u 
Table 7 Comparision of performance measures between the proposed and existing methods at $P=0.8$ p.u. and $Q=0.3$ p.u

\begin{tabular}{llllll}
\hline $\begin{array}{l}\text { Time domain } \\
\text { specifications/ } \\
\text { Performancelndices }\end{array}$ & $\begin{array}{l}\text { Kharitonov } \\
\text { Poly Root } \\
\text { Locus [36] }\end{array}$ & $\begin{array}{l}\text { Khartionov } \\
\text { Poly PSO } \\
{[37]}\end{array}$ & $\begin{array}{l}\text { Image set } \\
\text { Lead-Lag } \\
{[41]}\end{array}$ & $\begin{array}{l}\text { Image set } \\
\text { PID-PSS } \\
{[41]}\end{array}$ & $\begin{array}{l}\text { Proposed } \\
\text { PID-PSS }\end{array}$ \\
\hline Rise Time & $8.1266 \mathrm{e}-4$ & $9.7828 \mathrm{e}-4$ & $7.9823 \mathrm{e}-5$ & 0.0024 & $\mathbf{1 . 1 9 1 5 e - 4}$ \\
Settling Time & 2.954 & 3.204 & 2.232 & 2.194 & $\mathbf{1 . 9 8 9}$ \\
Peak value & 0.0009 & 0.0009 & 0.001 & 0.001 & $\mathbf{5 . 3 5 4 2 e - 4}$ \\
Peak time & 0.6500 & 0.6400 & 0.6500 & 0.69 & $\mathbf{0 . 5 9 0 0}$ \\
ISE & $7.6983 \mathrm{e}-7$ & $7.0825 \mathrm{e}-7$ & $6.0816 \mathrm{e}-7$ & $0.1092 \mathrm{e}-7$ & $\mathbf{0 . 6 9 6 7 2 e - 7}$ \\
IAE & $9.0728 \mathrm{e}-4$ & $8.3127 \mathrm{e}-4$ & $5.7750 \mathrm{e}-4$ & $8.3347 \mathrm{e}-4$ & $\mathbf{2 . 7 6 6 0 e - 4}$ \\
ITSE & $6.1336 \mathrm{e}-7$ & $5.6275 \mathrm{e}-7$ & $4.2605 \mathrm{e}-\mathbf{7}$ & $8.0200 \mathrm{e}-7$ & $\mathbf{0 . 5 6 8 4 7 e - 7}$ \\
ITAE & 0.0011 & 0.0010 & $5.1849 \mathrm{e}-4$ & $7.7943 \mathrm{e}-4$ & $\mathbf{3 . 0 2 6 2 e - 4}$ \\
\hline
\end{tabular}

$$
\left.\begin{array}{l}
a_{4}=[1,1] ; a_{3}=[20.22,20,22] \\
a_{2}=[233.8,425.3] ; a_{1}=[4247,8108] \\
a_{0}=[3900,8056] ; b=[21.71,30.188]
\end{array}\right\}
$$

The overall transfer function of the plant with PID PSS in the closed loop is given by:

$$
T(s)=\frac{-[21.71,30.18] s}{[1,1] s^{4}+[20.22,20.22] s^{3}+\left[233.8+21.71 k_{d}, 425.3+30.18 k_{d}\right] s^{2}}
$$

From (40) the characteristic equation of the closed loop transfer function is given by the following interval polynomial:

$$
\left.\begin{array}{l}
D(s, a)=[1,1] s^{4}+[20.22,20.22] s^{3}+\left[233.8+21.71 k_{d},\right. \\
\left.425.3+30.18 k_{d}\right] s^{2}+\left[4247+21.71 k_{p}, 8108+30.18 k_{p}\right] s \\
+\left[3900+21.71 k_{i}, 8056+30.18 k_{i}\right]
\end{array}\right\}
$$

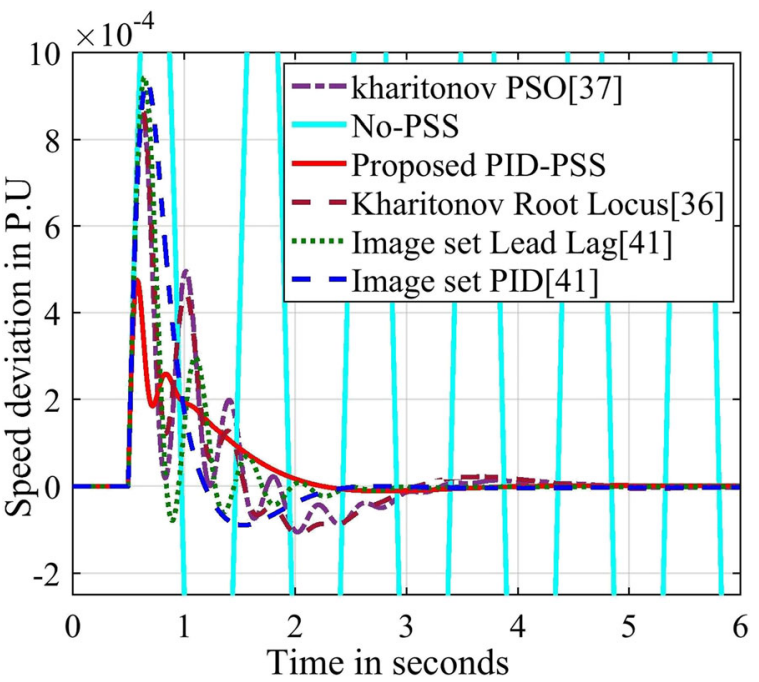

Fig. 17 Comparison of speed deviation response of the proposed with existing methods to 0.1 p.u. .torque disturbance at $P=1.2$ p.u. and $Q=0.2$ p.u

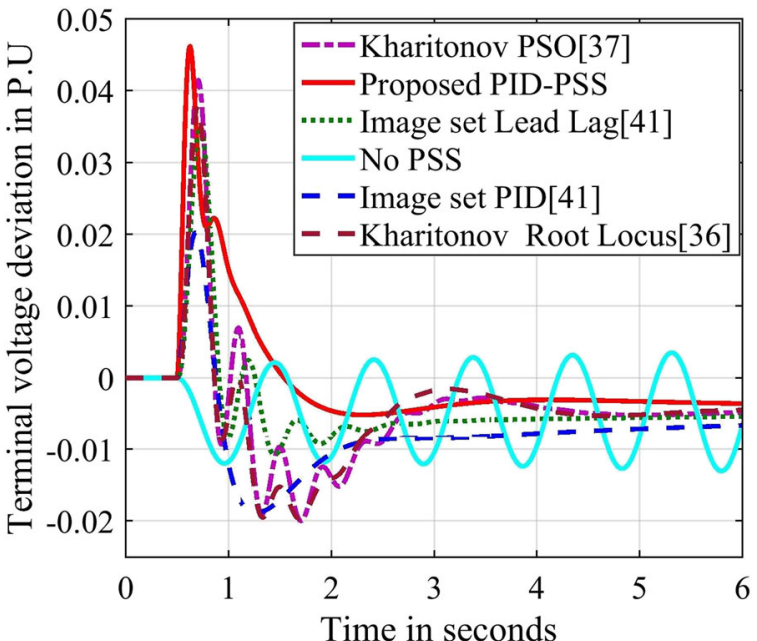

Fig. 18 Comparision of terminal voltage deviation response of the proposed with existing methods to 0.1 p.u. torque disturbance at $P=1.2$ p.u. and $Q=0.2$ p.u

Applying the new stability conditions given by (18)-(22) to (41), the following inequality constraints are obtained:

Constraint 1:

$$
\frac{\left[8056+30.18 k_{i}\right] * 20.22}{\left[4247+21.71 * k_{p}\right] *\left[233.8+21.71 * k_{d}\right]}-0.4655<0
$$

Constraint 2:

$$
\frac{\left[8108+30.18 k_{p}\right] * 1}{\left[233.8+21.71 * k_{d}\right] * 20.22}-0.4655<0
$$

Constraint 3:

$$
-233.8-21.71 * k_{d}<0
$$

Constraint 4:

$$
-4247-21.71 * k_{p}<0
$$

Table 8 Comparision of performance measures between the proposed and existing methods at $P=1.2$ p.u. and $Q=0.2 p . u$. $P=1.2 p$. uand $Q=0.2 p \cdot u$

\begin{tabular}{llllll}
\hline $\begin{array}{l}\text { Time domain } \\
\text { specifications/ } \\
\text { Performance Indices }\end{array}$ & $\begin{array}{l}\text { Kharitonov } \\
\text { Poly Root } \\
\text { Locus [36] }\end{array}$ & $\begin{array}{l}\text { Kharitonov } \\
\text { Poly PSO } \\
{[37]}\end{array}$ & $\begin{array}{l}\text { Image set } \\
\text { Lead-Lag } \\
{[41]}\end{array}$ & $\begin{array}{l}\text { Image set } \\
\text { IID-PSS } \\
{[41]}\end{array}$ & $\begin{array}{l}\text { Proposed } \\
\text { PID-PSS }\end{array}$ \\
\hline Rise Time & 0.0024 & $2.7269 \mathrm{e}-5$ & $8.5554 \mathrm{e}-5$ & 0.0032 & $\mathbf{1 . 4 1 1 5 e - 4}$ \\
Settling Time & 3.320 & 3.141 & 2.374 & 2.184 & $\mathbf{1 . 8 9 5}$ \\
Peak value & $8.6473 \mathrm{e}-4$ & $8.5661 \mathrm{e}-4$ & $9.4161 \mathrm{e}-4$ & $9.3236 \mathrm{e}-4$ & $\mathbf{4 . 7 7 8 3 e - 4}$ \\
Peak time & 0.6300 & 0.6300 & 0.6500 & 0.6700 & $\mathbf{0 . 5 8 0 0}$ \\
ISE & $1.5223 \mathrm{e}-7$ & $1.4698 \mathrm{e}-\mathbf{7}$ & $1.5204 \mathrm{e}-\mathbf{7}$ & $2.0622 \mathrm{e}-\mathbf{7}$ & $\mathbf{0 . 4 9 3 4 e - 7}$ \\
IAE & $4.0349 \mathrm{e}-4$ & $3.7200 \mathrm{e}-4$ & $2.8842 \mathrm{e}-4$ & $3.6083 \mathrm{e}-4$ & $\mathbf{2 . 3 1 5 5 e - 4}$ \\
ITSE & $1.2249 \mathrm{e}-\mathbf{7}$ & $1.1866 \mathrm{e}-\mathbf{7}$ & $1.0651 \mathrm{e}-\mathbf{7}$ & $1.4880 \mathrm{e}-\mathbf{7}$ & $\mathbf{0 . 4 0 0 2 e - 7}$ \\
ITAE & $5.1076 \mathrm{e}-4$ & $4.5924 \mathrm{e}-\mathbf{4}$ & $2.5746 \mathrm{e}-\mathbf{4}$ & $3.3132 \mathrm{e}-4$ & $\mathbf{2 . 4 9 8 9 e - 4}$ \\
\hline
\end{tabular}


Constraint 5:

$$
-3900-21.71 * k_{i}<0
$$

The controller parameters are tuned by minimizing the objective function (23) subject to satisfying the above inequalities (42)-(46) using FMINCON in MATLAB to achieve desired damping and settling time at light, nominal and heavy loading conditions. The $k_{p o}, k_{i o}$ and $k_{d o}$ are determined using the procedure described for Case study I. The obtained optimal PID-PSS controller values are:

$$
k_{p}=50 ; k_{i}=244.9695 ; \text { and } k_{d}=36.2937
$$

The system is simulated in MATLAB-SIMULINK using the Heffron-Philiphs model shown in Fig. 2 for light, nominal and heavy loading conditions. The performance of the proposed PID-PSS is evaluated by subjecting the plant to a 0.1 p.u. mechanical step disturbance for all the three cases. The speed deviation responses of the plant are shown in Figs. 19, 20 and 21. It is observed that even without PSS the system is stable for a $10 \%$ mechanical step disturbance but it takes a long time to reach steady state and the peak overshoot is high. The dynamic stability of the plant is improved by the addition of PSS. The settling time is around $4 \mathrm{~s}$ with single lead PSS [52], $2.5 \mathrm{~s}$ with double lead PSS [52], and $1.3 \mathrm{~s}$ with the proposed PID-PSS for all the three operating conditions. Thus, the proposed PID-PSS well damps out system oscillation for the given disturbance under the different loading conditions. In addition, the peak

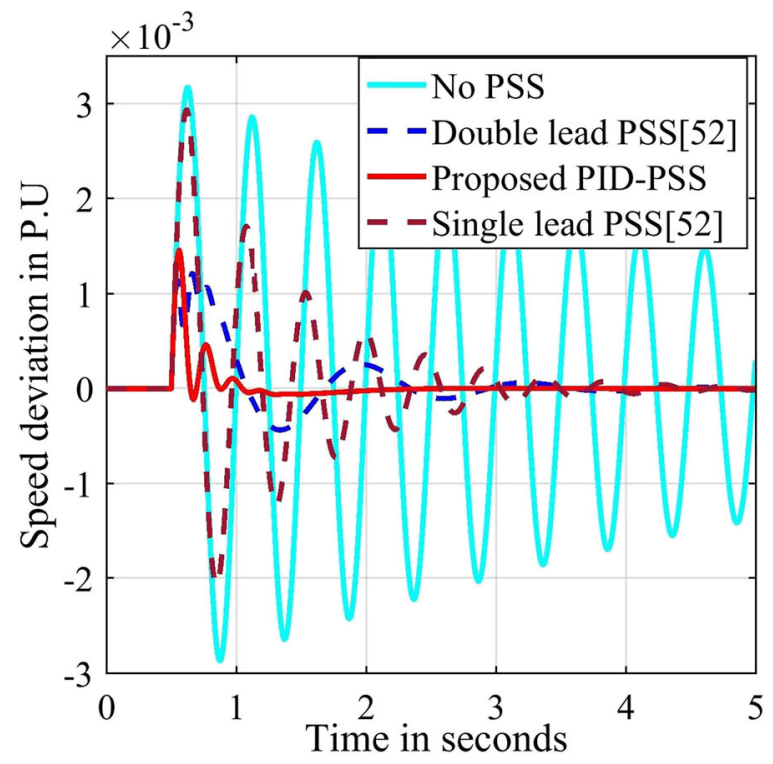

Fig. 19 Comparison of light load $(P=0.4$ p.u. and $Q=0.35$ p.u.) response of Barka-II Power station of the proposed with existing methods to 0.1 p.u. torque disturbance

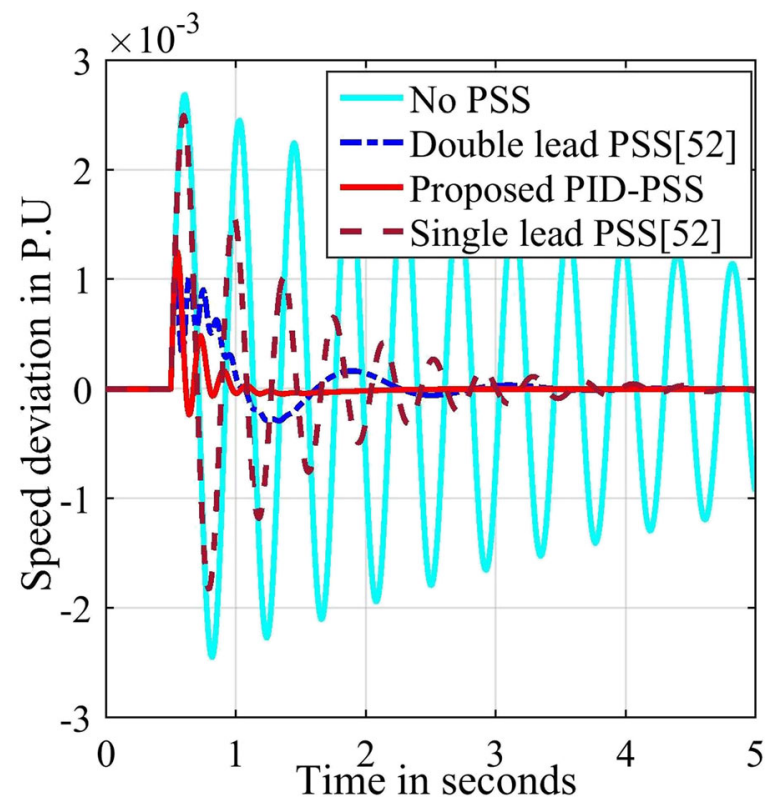

Fig. 20 Comparison of nominal load $(P=0.7$ p.u. and $Q=$ 0.525 p.u.) response of Barka-II Power station of the proposed with existing methods to 0.1 p.u. torque disturbance

overshoot with single lead PSS is higher than those of the proposed and double lead PSS controllers, while the latter two are similar. It can also be noted that the proposed PID-PSS produces less oscillation than the double lead PSS controller, hence creating fewer shaft fatigue effects. Hence, it is concluded that the proposed PID-PSS provides better dynamic performance for the



Fig. 21 Comparison of heavy load ( $P=1$ p.u. and $Q=0.875$ p.u.) response of Barka-II Power station of the proposed with existing methods to 0.1 p.u. torque disturbance 
uncertainties present in the system than the other controllers [52] under all operating conditions.

\section{Conclusion}

A simple robust PID-PSS design methodology is proposed to enhance the dynamic stability of an SMIB system for a wide range of operating conditions. The Heffron-Pilliphs model developed by DeMello and Concordia is used for small signal stability analysis, whereas the SMIB system is represented by a fourth order transfer function in an interval system. The extreme values of the coefficients are computed for a specified range of $P$ and $Q$, and the computationally simple stability conditions with five inequality constraints are developed for the SMIB interval system. The robust PID-PSS parameters are tuned using FMINCON solver in MATLAB. The performance of the proposed robust PID-PSS is demonstrated with two case studies for different operating conditions. Simulation results show that the proposed robust PID-PSS has superior performance and provides better damping of low frequency oscillation when subjected to a small load disturbance for a wide range of operating conditions, when compared to the available methods in the literature.

\section{Abbreviations \\ $V_{t}$ : Terminal voltage; $E_{q}^{\prime}$ : Voltage proportional to direct axis flux linkages; $E_{q}$ : Induced emf proportional to field current; $E_{f d}$ : Generator field voltage; $\delta$ : Angle between quadrature axis and infinite bus; $M$ : Inertia constant $=2 \mathrm{H}$, seconds; $T_{e}$ : Electrical torque; $V$ : Infinite bus voltage; $K_{E}$ : Exciter gain constant; $T_{E}$ : Exciter time constant; $x_{d}^{\prime}$ : Generator direct axis transient reactance; $x_{d}, x_{q}$ : Generator direct and quadrature-axis synchronous reactance respect- ively; $x_{e}$ : External (line) reactance; $\omega$ : Speed deviation; $T_{d o}$ : Open circuit direct axis transient time constant; U: Control signal (PSS) output; $P, Q$ : Real and reactive power, respectively}

\section{Acknowledgements}

Dr. Vasu Ganji, Mr. Dasu Butti.

\section{Authors' contributions}

MRR and ASV conceived the presented idea. MS \& ASV formulate the methodology. ASV performed computations and simulate the results on a test system. MRR and MS supervised the findings of the work with constructive suggestions, verified the results and edited the manuscript. The authors read and approved the final manuscript.

\section{Author's information}

A S V Vijaya Lakshmi: The author completed her B. Tech and M. Tech from JNTU Kakinada and pursuing her PhD in JNTU Kakinada. Her research interests include Control aspects of Power Systems and optimization techniques..

Manyala Ramalinga Raju received the Masters degree from REC Warangal and PhD degree from JNTU University, India. Presently working as ViceChancellor, JNT University Kakinada, Kakinada. He has presented many research papers in various national and international conferences and journals. His research interests include energy management, conservation and auditing, distribution generation and IT applications in power utility companies. Mangipudi Siva Kumar: The author completed his M.E and PhD from Andhra University. He is presently working as Professor in EEE Department, Gudlavalleru Engineering College, Gudlavalleru. He has contributed more than 40 technical papers in various referred journals and conference. He is a life member of ISTE, member of IEEE and IAEng and Fellow of Institution of Engineers. His research interests include model order reduction, interval system analysis, design of PI/PID controllers for Interval systems, sliding mode control and Soft computing Techniques.

\section{Funding}

This work is carried out without the support of any funding agency.

Availability of data and materials

Please contact author for data material request.

\section{Competing interests}

The authors declare that they have no competing interests.

\section{Author details}

'Department of EEE, G.V.P College of Engineering for Women,

Visakhapatnam, India. '2Department of EEE, JNTU Kakinada, Kakinada, India.

${ }^{3}$ Department of EEE, Gudlavalleru Engineering College, Gudlavalleru, Andhra

Pradesh, India.

Received: 16 April 2020 Accepted: 16 August 2020

Published online: 29 September 2020

\section{References}

1. Demello, F. P., \& Concordia, C. (1969). Concepts of synchronous machine stability as affected by excitation control. IEEE Transactions on Power Apparatus and Systems, PAS-88(4), 316-329.

2. Kundur, P. (1994). Power system stability and control. USA: McGram-hill.

3. Sauer, P. W., \& Pai, M. A. (1998). Power system dynamics and stability. New Jersey: Prentice-Hall, Inc.

4. Anderson, P. M., \& Fouad, A. A. (1997). Power system control and stability. New Delhi: Wiley ISBN: 978-81-265-1818-0

5. Chakrabarti, A. (2013). Power system dynamics and simulation. Delhi: PHI Learning Private limited.

6. Padiyar, K. R. (2002). Power system dynamics stability and control. Hyderabad: BS Publications

7. Kundur, P. Klein, M. Rogers, G. J. \& Zywno, M. S. (1989). Application of power system stabilizers for enhancement of overall system stability. IEEE Transactions on Power Apparatus and Systems, PWRS-4, 614-626.

8. Liu, W., Venayagamoorthy, G. K., \& Wunsch, D. C. (2013). Design of an adaptive neural network-based power system stabilizer. Neural Networks, 16 , 891-898.

9. Li, X. M., Fu, J. F., Zhang, X. Y., Cao, H., Lin, Z. W., \& Niu, Y. G. (2018). A neural power system stabilizer of DFIGs for power system stability support International Transactions on Electrical Energy Systems, 28(6), e2547.

10. Awadallah, M. A., \& Soliman, H. M. (2009). A neuro fuzzy adaptive power system stabilizer using genetic algorithms. Electric Power Components \& Systems, 37, 158-173.

11. Soliman, H. M., \& Metwally, K. A. E. I. (2017). Robust pole placement for power systems using two-dimensional membership fuzzy constrained controllers. IET Generation Transmission and Distribution, 11(16), 3966-3973.

12. Zakirhussain, F., Ibrahim, E., Suleyman Sungur, T., \& Shah Jahan, S. (2018). A robust PID power system stabilizer Design of Single Machine Infinite bus system using firefly algorithm. Gazi University Journal of Science, 31(1), 155172.

13. Abdel-Magid, Y. L., \& Abido, M. A. (2003). Optimal multiobjective design of robust power system stabilizers using genetic algorithms. IEEE Transactions on Power Systems, 18(3), 1125-1132.

14. Sambariya, D. K., \& Prasad, R. (2015). Design of Robust PID power system stabilizer for multimachine power system using $\mathrm{HS}$ algorithm. American Journal of Electrical and Electronic Engineering, 3(3), 75-82.

15. Dasu, B., Siva Kumar, M., \& Srinivasa Rao, R. (2019). Design of robust modified power system stabilizer for dynamic stability improvement using particle swarm optimization technique. Ain Shams Engineering Journal, 10(4), 769-783.

16. Dasu, B., Siva Kumar, M., \& Srinivasa, R. R. (2018). Optimal Design of Modified Power System Stabilizer Using Multi Objective Based bio inspired algorithms. International Journal of Energy Optimization and Engineering, 7(4) 17-55.

17. Abido, M. A. (2002). Optimal design of power system stabilizers using particle swarm optimization. IEEE Transactions on Energy Conversion, 17(3), 406-413.

18. Abido, M. A (2001). Particle swarm optimization for multi machine power system stabilizer design. IEEE/PES, Summer Meeting, 3, 1346-1351. 
19. Hasanvand, H., Babak, M. M., Aavan, R., \& Amraee, T. (2015). Application of polynomial control to design a robust oscillation-damping controller in a multimachine power system. ISA Transactions, 59, 343-353.

20. Naresh, G., Ramalinga Raju, M., \& Narasimham, S. V. L. (2016). Coordinated design of power system stabilizers and TCSC employing improved harmony search algorithm. Swarm and Evolutionary Computation, 27, 169-179.

21. Wang, H. F. (1999). Phillips-Heffron model of power systems installed with STATCOM and applications. IEE Proceedings - Generation, Transmission and Distribution, 146(5), 521-527.

22. Hasanvand, H., Arvan, M. R., Mozaari, B., \& Amraee, T. (2016). Coordinated design of PSS and TCSC to mitigate inter-area oscillations. Electrical Power and Energy Systems, 78(5), 194-206.

23. Malik, O. P., Hope, G. S., \& Ramanujan, V. (1976). Real time model reference adaptive control of synchronous machine excitation. IEEE-PES Winter Meeting, 178, 297-304.

24. Soliman, M., Elshafei, A. L., Bendary, F., \& Mansou, W. (2009). Design of a robust fuzzy power system stabilizer. Control and Intelligent Systems, 37(4), 649-664.

25. Soliman, H. M. (2016). Resilient observer-based power system stabilizers. Transactions of the Institute of Measurement and Control, 38(8), 981-991.

26. Rao, P. S., \& Sen, I. (2000). Robust pole placement stabilizer design using linear matrix inequalities. IEEE Transactions on Power Apparatus and Systems, 15(2), 313-319.

27. Werner, H., Korba, P., \& Chen Yang, T. (2003). Robust tuning of power system stabilizers using LMI techniques. IEEE Transactions on Control Systems Technology, 11(1), 147-2003.

28. Chen, S., \& Malik, O. (1996). H $_{\infty}$ optimization-based power system stabilizer design. IEE Proceedings on Generation, Transmission and Distribution, 193, 253-257.

29. Li, G., Lie, T. T., Soh, C. B., \& Yang, G. H. (2002). Design of state-feedback decentralized $H_{\infty}$ controllers in power systems. Electrical Power and Energy Systems, 24, 601-610.

30. Yue, M., \& Schlueter, R. (2003). $\mu$-synthesis power system stability design using a bifurcation subsystem based methodology. IEEE Transactions on Power Apparatus and Systems, 18(4), 1497-1507.

31. Yang, T. C. (1997). Applying $H_{\infty}$ optimization method to power system stabilizer design part I: Single machine infinite bus systems. Electrical Power and Energy Systems, 19(1), 29-35.

32. Soliman, M., Emara, H., Elshafei, A., Bahgat, A., \& Malik, O. P. (2008). Robust output feedback power system stabilizer design: An LMI approach. IEEE Power and Energy Society General meeting. https://doi.org/10.1109/PES.2008.4596450.

33. Scherer, C., Gahinet, P., \& Chilali, M. (1997). Multiobjective output-feedback control via LMI optimization. IEEE Transactions on Automatic Control, 42, 896-911.

34. Soliman, H. M., \& Yousef, H. (2015). Saturated robust power system stabilizers. International Journal of Electrical Power \& Energy Systems, 73(12), 608-614.

35. Soliman, M. (2015). Robust non-fragile power system stabilizer. Electrical Power and Energy Systems, 64, 626-634.

36. Soliman, H. M., Elshafei, A. L., Shaltout, A., \& Morsi, M. F. (2000). Robust power system stabilizer. IEE Proceedings - Generation, Transmission and Distribution, 147(5), 285-229.

37. Metwally, K. A., El Elshafe, A. L., \& Soliman, H. M. (2006). A robust powersystem stabilizer design using swarm optimization. International Journal of Modelling, Identification and Control, 1(4), 263-271.

38. Soliman, H. M., Bayoumi, E. H. E., \& Hassan, M. F. (2009). Power system stabilizer Design for Minimal Overshoot and Control Constraint Using Swarm Optimization. Electric Power Components \& Systems, 37, 111-126.

39. Rigatos, G., \& Saino, P. (2011). Design of robust electric power system stabilizers using Kharitonov's theorem. Mathematics and Computers in Simulation, 82, 181-191.

40. Soliman, M. (2014). Parameterization of robust three-term power system stabilizers. Electric Power Systems Research, 117(12), 172-184.

41. Soliman, M. (2016). Robust power system stabilizer design via interval arithmetic. International Journal of Modelling, Identification and Control, 25(4), 287-300.

42. Soliman, H. M., Morsi, M. F., Hassan, M. F., \& Awadallah, M. A. (2009). Power system reliable stabilization with actuator failure. Electric Power Components \& Systems, 37, 61-77.

43. Dasu, B., SivaKumar, M., \& Srinivasrao, R. (2019). Interconnected multimachine power system stabilizer design using whale optimization algorithm. Protection and Control of Modern Power Systems. https://doi.org/ 10.1186/s41601-019-0116-6.

44. Essallah, S., Bouallegue, A., \& Khedher, A. (2019). Integration of automatic voltage regulator and power system stabilizer: Small-signal stability in DFIG-based wind farms. Protection and Control of Modern Power Systems, 7(5), 1115-1128.
45. Digvijay, V. N., \& Murty, M. S. R. (2020). Reconfigurable control as actuator fault-tolerant control design for power oscillation damping. Protection and Control of Modern Power Systems. https://doi.org/10.1186/s41601-020-0151-3.

46. Patre, B. M., \& Deore, P. J. (2007). Robust stability and performance for interval process plants. ISA Transactions, 46(3), 343-349.

47. Nie (1976). A new class of criterion for the stability of the polynomial. Act Mechnicasinica, 15(1), 110-116.

48. Chao, L., Zhao, Y., Kun, M., Liang, T., \& Yingduo, H. (2015). Wide-area power system stabilizer based on model-free adaptive control. IET Control Theory Appl, 9(13), 1996-2007.

49. Haseena, K. A., Jeevamma, J., \& Abraham, T. M. (2018). Fractional order leadlag compensator based multi-band power system stabilizer design using a hybrid dynamic GA-PSO algorithm. IET Generation, Transmission \& Distribution, 12(13), 3248-3260.

50. Salgotra, A., \& Somanath, P. (2018). A frequency domain model based design of PSS \& TCSC controller for damping the small signal oscillations in the power system. Int Trans Electr Energ Syst. https://doi.org/10.1002/etep. $2742 \mathrm{~h}$.

51. Drof, R. C., \& Bishop, R. H. (2011). Modern control systems. New Jersy: Pearson Education Inc

52. Soliman, H., Mohammed, A., Sheriyani, H. -Al., Azakawi, H. -Al., \& Qutaiti Ali, -Al. (2019). Robust Power System Stabilizer Design using Khartinov's Theorem: A Case Study. Electrical Science \& Engineering. https://doi.org/10. 30564/ese.v1i1.1187.

53. Bhattacharyya, S. P., Chapelett, H., \& Keel, L. H. (1995). Robust control: The parametric approach. New Jersey: Prentice hall Inc

54. Matlab-Optimization Toolbox TM, User guide, R2013b. The MathWorks, Inc., 2013.

\section{Submit your manuscript to a SpringerOpen ${ }^{\circ}$ journal and benefit from:}

- Convenient online submission

- Rigorous peer review

- Open access: articles freely available online

- High visibility within the field

- Retaining the copyright to your article

Submit your next manuscript at $>$ springeropen.com 